\title{
Building a neuroscience of pleasure and well-being
}

\author{
Kent C Berridge ${ }^{1 * \dagger}$ and Morten L Kringelbach ${ }^{2,3^{*}+}$
}

\author{
* Correspondence: \\ berridge@umich.edu; Morten. \\ Kringelbach@queens.ox.ac.uk \\ ${ }^{1}$ Department of Psychology, \\ University of Michigan, Ann Arbor, \\ USA \\ 2Department of Psychiatry, \\ Warneford Hospital, University of \\ Oxford, Oxford, UK \\ Full list of author information is \\ available at the end of the article
}

\begin{abstract}
Background: How is happiness generated via brain function in lucky individuals who have the good fortune to be happy? Conceptually, well-being or happiness has long been viewed as requiring at least two crucial ingredients: positive affect or pleasure (hedonia) and a sense of meaningfulness or engagement in life (eudaimonia). Science has recently made progress in relating hedonic pleasure to brain function, and so here we survey new insights into how brains generate the hedonic ingredient of sustained or frequent pleasure. We also briefly discuss how brains might connect hedonia states of pleasure to eudaimonia assessments of meaningfulness, and so create balanced states of positive well-being.
\end{abstract}

Results: Notable progress has been made in understanding brain bases of hedonic processing, producing insights into that brain systems that cause and/or code sensory pleasures. Progress has been facilitated by the recognition that hedonic brain mechanisms are largely shared between humans and other mammals, allowing application of conclusions from animal studies to a better understanding of human pleasures. In the past few years, evidence has also grown to indicate that for humans, brain mechanisms of higher abstract pleasures strongly overlap with more basic sensory pleasures. This overlap may provide a window into underlying brain circuitry that generates all pleasures, including even the hedonic quality of pervasive well-being that detaches from any particular sensation to apply to daily life in a more sustained or frequent fashion.

Conclusions: Hedonic insights are applied to understanding human well-being here. Our strategy combines new findings on brain mediators that generate the pleasure of sensations with evidence that human brains use many of the same hedonic circuits from sensory pleasures to create the higher pleasures. This in turn may be linked to how hedonic systems interact with other brain systems relevant to selfunderstanding and the meaning components of eudaimonic happiness. Finally, we speculate a bit about how brains that generate hedonia states might link to eudaimonia assessments to create properly balanced states of positive well-being that approach true happiness.

\section{Background}

From Aristotle to contemporary positive psychology, well-being or happiness has been usefully proposed to consist of at least two ingredients: hedonia and eudaimonia (Aristotle 2009; Seligman et al. 2005). While definitions of these by philosophers and psychologists have varied, most generally agree that hedonia at least corresponds psychologically to a state of pleasure. Thus a particularly important topic for hedonic psychology and affective neuroscience is to understand how pleasure is generated by brain mechanisms so as to contribute to well-being. Fortunately, deciphering hedonia

(c) 2011 Berridge and Kringelbach; licensee Springer. This is an Open Access article distributed under the terms of the Creative Commons Attribution License (http://creativecommons.org/licenses/by/2.0), which permits unrestricted use, distribution, and reproduction in any medium, provided the original work is properly cited. 
in the brain is a task in which considerable progress has already been made. Eudaimonia by comparison may be more difficult to define philosophically or approach scientifically, but most agree it corresponds to some cognitive and/or moral aspect of a life lived well and not to any mere emotional feeling. We view eudaimonia to mean essentially a life experienced as valuably meaningful and as engaging. Thus, for psychological neuroscience of the future another major goal will be to uncover how such experiences are reflected in patterns of brain activity (Urry et al. 2004).

Conceptually, hedonic processing and eudaimonic meaningfulness are very different from each other. Yet, empirically, in real people well-being has been found to involve both together. High questionnaire scores for hedonia and eudaimonia typically converge in the same happy individual (Diener et al. 2008; Kuppens et al. 2008). That is, if a person self-reports to be hedonically happy, then that same person is also likely to report a high sense of positive meaningfulness in life. For example, in happiness surveys, over 80 percent of people rate their overall eudaimonic life satisfaction as "pretty to very happy". Comparably, 80 percent also rate their current hedonic mood as positive (for example, positive 6-7 on a 10 point valence scale, where 5 is hedonically neutral (Diener et al. 2008; Kuppens et al. 2008). A lucky few may even live consistently around a hedonic point of 8 . Beyond that, however, there may be such a thing as being too happy. Excessively higher hedonic scores above 8 may actually impede eudaimonic attainment of life success, however, as measured by wealth, education, or political participation (Oishi et al. 2007).

The tendency of pleasure and meaningfulness ratings to cohere together opens a potential window of opportunity to the neuroscientific study of both aspects of wellbeing (Kringelbach and Berridge 2009; Urry et al. 2004). If both hedonia and eudaimonia co-occur in the same happy people, then identifying neural markers of one may give a toehold into identifying the other. Still, most would probably agree that eudaimonic happiness poses harder challenges to psychology and neuroscience. It is difficult even to define life meaningfulness in a way as to avoid dispute, let alone to tie a happy sense of meaningfulness to any specific brain patterns of activation. The difficulties of approaching eudaimonic meaning are not insurmountable in principle, but for the foreseeable short term seem likely to remain obstacles to affective neuroscience.

Therefore here we will focus mostly upon the hedonia or pleasure aspect of wellbeing. The pleasure aspect is most tractable, and can be inspected against a growing background of understanding of the neural foundations for specific pleasures. Supporting a hedonic approach to happiness, happy people typically feel more pleasure in life. Indeed it has been suggested that the best and simplest measure of well-being may be to merely ask people how they hedonically feel right now-again and again-so as to track their hedonic accumulation across daily life (Kahneman 1999). Such repeated self-reports of hedonic states could also be used to identify more stable neurobiological hedonic brain traits that dispose particular individuals toward happiness. Conversely, it will probably not be much disputed that the capacity for pleasure is essential to normal well-being. Pathological loss of pleasure can be devastating, and precludes well-being. Our aim is to use findings from recent research on brain mechanisms of pleasure to ask how to higher states of hedonia might be generated to produce well-being, and conversely what might go wrong in affective disorders (Berridge and Kringelbach 2008; Kringelbach and Berridge 2010; Leknes and Tracey 2010; Smith et al. 2010). 
We note in passing that our focus on the hedonia component of happiness should not be confused with hedonism, which is the pursuit of pleasure for pleasure's own sake, and more akin to the addiction features we describe below. Also, to focus on hedonics does not deny that some ascetics may have found bliss through painful selfsacrifice, but simply reflects that positive hedonic tone is indispensable to most people seeking happiness (Bok 2010; Bok 2010; Diener et al. 2008; Gilbert 2006; Kahneman 1999; Seligman et al. 2005).

\section{Sensory pleasures: From sensation to 'liking' to hedonic feelings}

First, what is pleasure? Pleasure is never merely a sensation, even for sensory pleasures (Frijda 2010; Katz, 2006; Kringelbach 2010; Kringelbach and Berridge 2010; Ryle 1954). Instead it always requires the recruitment of specialized pleasure-generating brain systems to actively paint an additional "hedonic gloss" onto a sensation. Active recruitment of brain pleasure-generating systems is what makes a pleasant experience 'liked'.

The capacity of certain stimuli, such as a sweet taste or a loved one, to reliably elicit pleasure - to nearly always be painted with a hedonic gloss - reflects the privileged ability of such stimuli to activate those hedonic brain systems responsible for manufacturing and applying the gloss. Hedonic brain systems are well-developed in the brain, spanning subcortical and cortical levels, and are quite similar across humans and other animals.

Some might be surprised by high similarity across species, or by substantial subcortical contributions, at least if one thinks of pleasure as uniquely human and as emerging only at the top of the brain. The neural similarity indicates an early phylogenetic appearance of neural circuits for pleasure and a conservation of those circuits, including deep brain circuits, in the elaboration of later species, including humans. Substantial mechanisms for pleasure would be selected and conserved only if they ultimately served a central role in fulfilling Darwinian imperatives of gene proliferation via improved survival and procreation, suggesting the capacity for pleasure must have been fundamentally important in evolutionary fitness (Berridge and Schulkin 1989; Cabanac 2010; Darwin 1872; Nesse 2002; Panksepp 1998; Rolls 2005; Schulkin 2004; Tindell et al. 2006).

Pleasure as an adaptive evolutionary feature is not so hard to imagine. For example, tasty food is one of the most universal routes to pleasure, as well as an essential requirement to survival. Not accidentally, food is also is one of the most accessible experimental methods available to psychology and neuroscience studies of pleasure (Berridge et al. 2010; Gottfried 2010; Kringelbach 2005; Kringelbach and Berridge 2010; Peciña Smith and Berridge, 2006; Rozin 1999; Veldhuizen et al. 2010). Much of what we will say here comes from such studies.

Beyond food, sex is another potent and adaptive sensory pleasure which involves some of the same brain circuits (Geogiadis and Kortekaas 2010; Komisaruk et al. 2010). Many other special classes of stimuli also appear tap into the same limbic circuits. Even rewarding drugs of abuse are widely viewed to hijack the same hedonic brain systems that evolved to mediate food, sex and other natural sensory pleasures (Everitt et al. 2008; Kelley and Berridge 2002; Koob and Volkow 2010).

Another fundamental pleasure is social interaction with conspecifics, which draws on overlapping neural systems and is important even from an evolutionary perspective 
(Aragona et al. 2006; Britton et al. 2006; Frith and Frith 2010; King-Casas et al. 2005; Kringelbach et al. 2008; Leknes and Tracey 2008). In fact, it might well be that in humans, at least, the social pleasures are often as pleasurable as the basic sensory pleasures.

Most uniquely, humans have many prominent higher order, abstract or cultural pleasures, including personal achievement as well as intellectual, artistic, musical, altruistic, and transcendent pleasures. While the neuroscience of higher pleasures is in relative infancy, even here there seems overlap in brain circuits with more basic hedonic pleasures (Frijda 2010; Harris et al. 2009; Leknes and Tracey 2010; Salimpoor et al. 2011; Skov 2010; Vuust and Kringelbach 2010). As such, brains may be viewed as having conserved and re-cycled some of the same neural mechanisms of hedonic generation for higher pleasures that originated early in evolution for simpler sensory pleasures.

\section{Identifying pleasure generators in the brain}

A state of positive affect may appear in experience to be a unitary process, but affective neuroscience has indicated that even the simplest pleasant experience, such as a mere sensory reward, is actually a more complex set of processes containing several psychological components, each with distinguishable neurobiological mechanisms (Berridge et al. 2009; Kringelbach and Berridge 2009; Leknes and Tracey 2010). These include at least the three psychological components of wanting, liking and learning, and each has both conscious and non-conscious sub-components. Liking is the actual pleasure component or hedonic impact of a reward, wanting is the motivation for reward and learning includes the associations, representations and predictions about future rewards based on past experiences. Each of these components plays a central role in the cyclical time course of pleasure (see Figures 1 and 2).

We distinguish between the conscious and non-conscious aspects of these sub-components because both aspects exist in people (Winkielman et al. 2005). And at least the latter can also be studied in other animals in ways that help reveal the underlying neural generating mechanisms. At the potentially non-conscious level, we use quotation marks to indicate that we are describing objective, behavioral or neural measures of these underlying brain processes. As such, 'liking' reactions result from activity in identifiable brain systems that paint hedonic value on a sensation such as sweetness. Similarly, 'wanting' includes incentive salience or motivational processes within reward that mirror hedonic 'liking' and make stimuli into motivationally attractive incentives, when incentive salience is attributed to stimulus representations by mesolimbic brain systems. Finally, 'learning' includes a wide range of processes linked to implicit knowledge as well as associative conditioning, such as basic Pavlovian and instrumental associations.

At the conscious level, liking is the conscious experiences of pleasure, in the ordinary sense of the word, which may be elaborated out of subcortical core 'liking' reactions by cognitive brain mechanisms of awareness. Conscious wanting includes conscious desires for incentives or cognitive goals, while conscious learning includes the updating of explicit and cognitive predictions (Friston and Kiebel 2009; Zhang et al. 2009).

This conscious experience of pleasure is so striking that that pleasure has seemed purely subjective by definition to many thinkers. But related to the notion that pleasure naturally evolved, we maintain that pleasure also has objective aspects that can be 


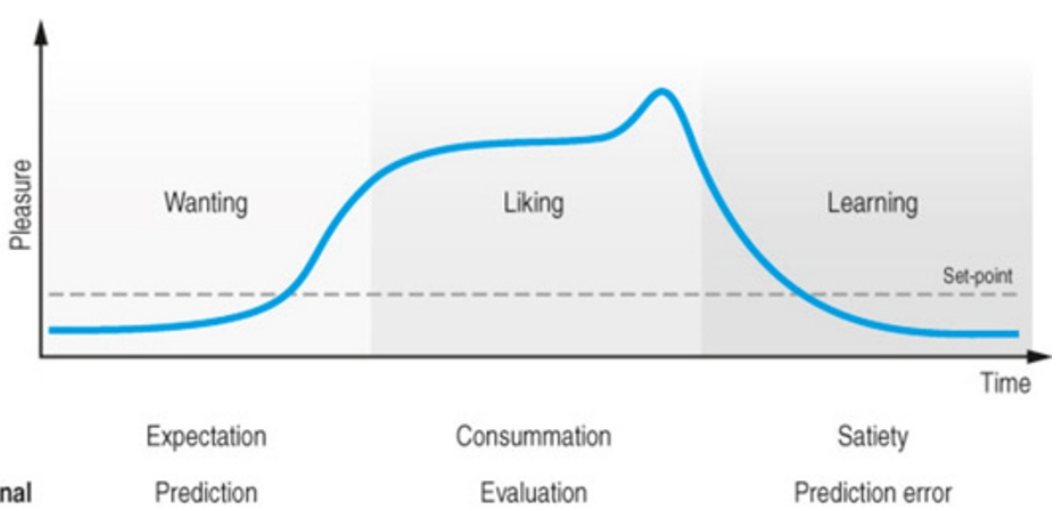

Figure 1 Pleasure cycles. One way to view the difference between pleasure 'liking' and other components of reward is as cyclical time course common to many everyday moments of positive affect. Typically, rewarding moments go through a phase of expectation or wanting for a reward, which sometimes leads to a phase of consummation or liking with the reward that can have a peak level of pleasure (e.g. encountering a loved one, a tasty meal, sexual orgasm, drug rush, winning a gambling bet). This can be followed by a satiety or learning phase, where one learns and update our predictions for the reward. These various phases have been identified at many levels of investigation of which the recent research on the computational mechanisms underlying prediction, evaluation and prediction error are particularly interesting (Friston and Kiebel 2009; Zhang et al. 2009). Note, however, that some rewards might possibly lack a satiety phase (suggested candidates for brief or missing satiety phase have included money, some abstract rewards and some drug and brain stimulation rewards that activate dopamine systems rather directly).

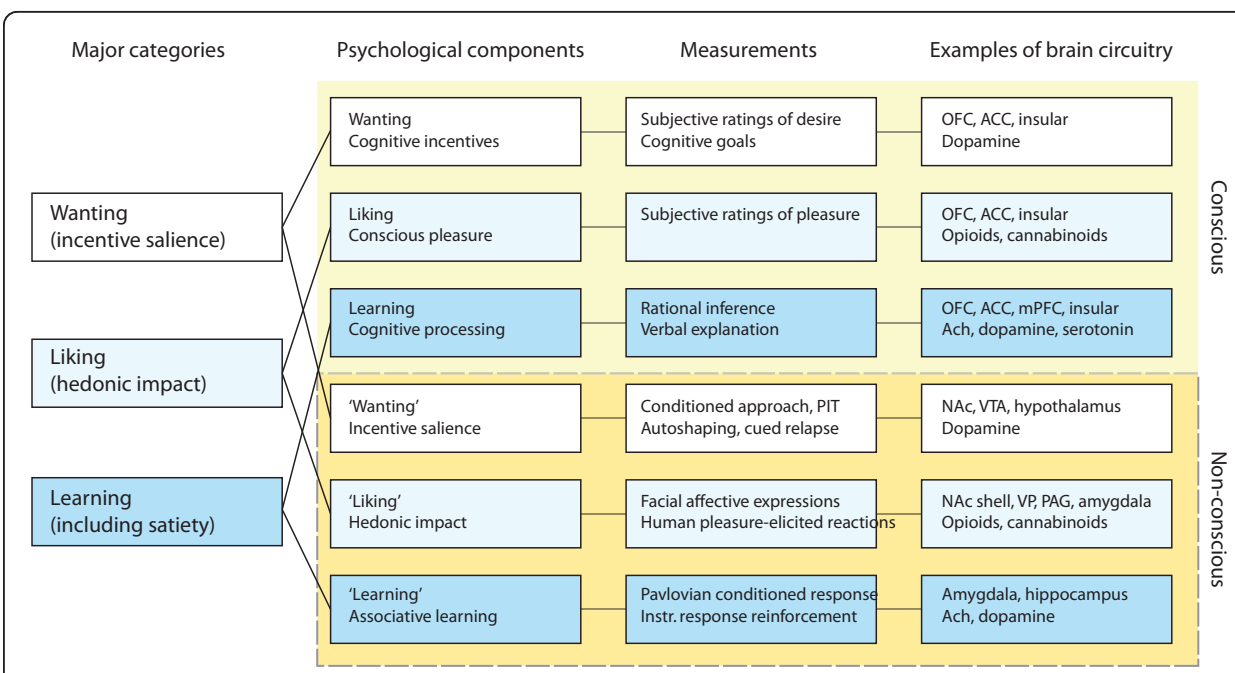

Figure 2 Measuring reward and hedonia. Hedonic reward processes related to well-being involve multifaceted psychological components. Major processes within reward (first column) consist of wanting or incentive salience (white), learning (blue), and - most relevant to happiness - pleasure liking or hedonic impact (light blue). Each of these contains explicit (top rows, light yellow) and implicit (bottom rows, yellow) psychological components (second column) that constantly interact and require careful scientific analysis to tease apart. Explicit processes are consciously experienced (e.g. explicit pleasure and happiness, desire, or expectation), whereas implicit levels of the same psychological processes are potentially unconscious in the sense that they can operate at a level not always directly accessible to conscious experience (implicit incentive salience, habits and 'liking' reactions), and must be further translated by other mechanisms into subjective feelings. Measurements or behavioral procedures that are especially sensitive markers of the each of the processes are listed (third column). 
detected in brain and mind. Note again, however, the underlying similarities of brain mechanisms for generating sensory pleasures in the brains of most mammals, both humans and nonhumans alike (Figure 3). It seems unlikely so much neural machinery would have been selected and conserved across species if it had no function. Basic pleasure reactions have always had objective consequences, and brain mechanisms for hedonic reactions have long been functionally useful - even before any additional mechanisms appeared that characterize any human-unique aspects of subjective feelings of pleasure. In a sense, we suggest hedonic reactions have been too important to survival for pleasure to be exclusively subjective. The objective aspect has also been invaluable in identifying the brain generators of pleasure described below.

\section{Results}

\section{Pleasure generators: hedonic hotspots in the brain}

How is pleasure actually generated within a brain? The brain appears frugal in mechanisms that that are causally sufficient to generate 'liking' or magnify pleasure to high levels. These few mechanisms are candidate brain wellsprings for hedonic happiness.

Compelling evidence for pleasure causation as increases in 'liking' reactions has so far been found for activation of only a few brain substrates, or hedonic hotspots. Those hedonic hotspots mostly reside -surprisingly, if one thought pleasure to reside primarily in the brain cortex - deep below the neocortex in subcortical structures. Our strategy to find such neural generators of pleasure gloss has relied on activating neural mechanisms underlying natural 'liking' reactions to intensely pleasant sensations. An example of 'liking' is the positive affective facial expression elicited by the hedonic impact of sweet tastes in newborn human infants (Figure 2), such as tongue protrusions that can lick the lips. By contrast, nasty bitter tastes instead elicit facial 'disliking' expressions of disgust such as gapes, nose and brow wrinkling, and shaking of the

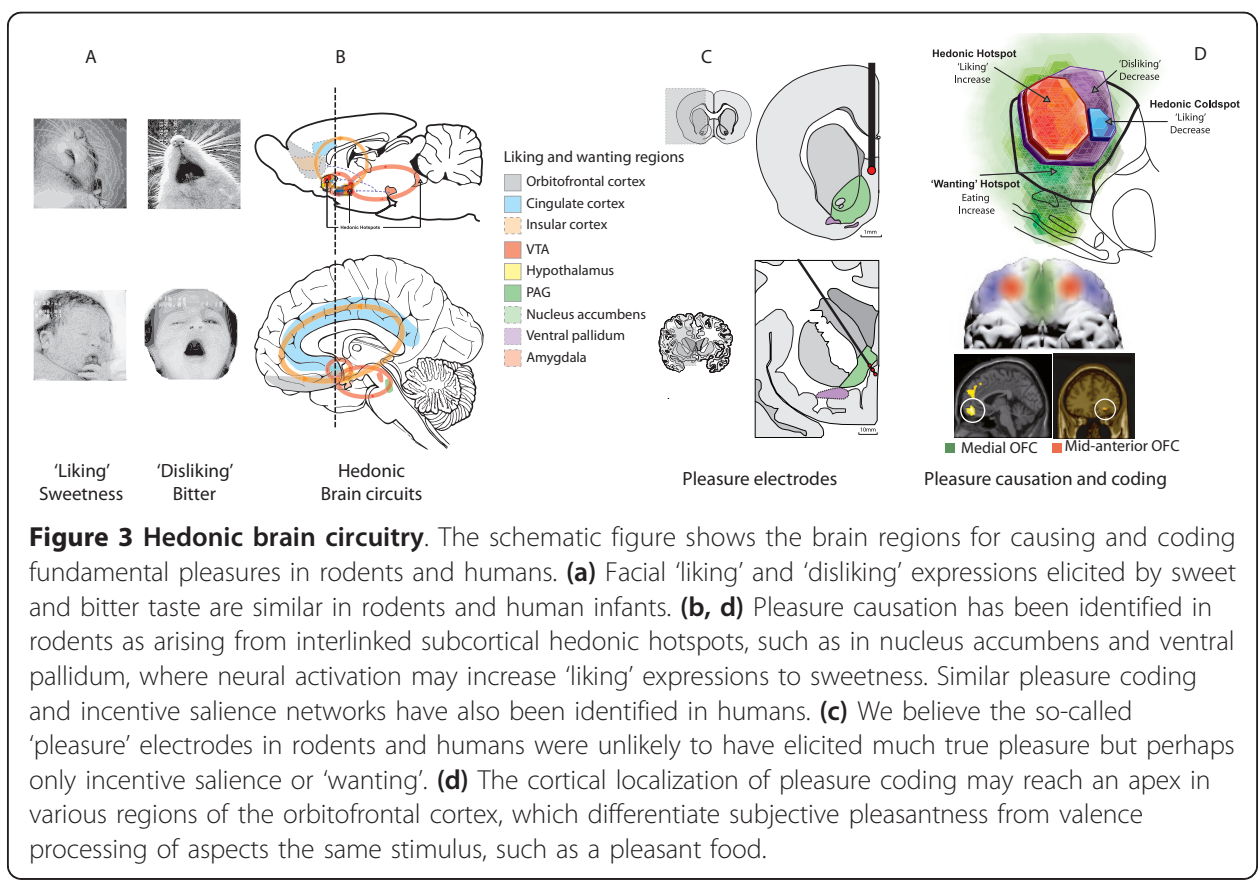


head. Many of these affective expressions are similar and homologous in humans, orangutans, chimpanzees, monkeys, and even rats and mice (for example, sharing features such as identical allometric timing laws in each species that scale speed of expressions to body size) (Grill et al. 1984; Grill and Norgren 1978; Steiner 1973; Steiner et al. 2001). Homology in origin of 'liking' reactions implies that the underlying hedonic brain mechanisms are similar in humans and other animals, opening the way for an affective neuroscience of pleasure generators that bridges both.

\section{Subcortical hedonic hotspots in nucleus accumbens, ventral pallidum and brainstem}

Some insight into pleasure-causing circuitry of human brains has been gained by affective neuroscience studies in rodents in which the hedonic hotspots are neurochemically stimulated to magnify a sensory pleasure, and so reveal the location and neurotransmitter identity of the generating mechanism for intense 'liking'. A hedonic hotspot is capable of generating enhancements of 'liking' reactions to a sensory pleasure such as sweetness, when opioid, endocannabinoid or other hedonic neurochemical receptor circuits within the hotspot are stimulated (Mahler et al. 2007; Peciña and Berridge 2005; Peciña et al. 2006; Smith and Berridge 2005). In rodent studies, the hotspots can be activated by painless microinjections of drug droplets that stimulate neurotransmitter receptors on nearby neurons. Within the hotspot, drug microinjections activate pleasure-generating systems to magnify the hedonic impact of a sweet taste, whereas outside the border of the hotspot the same microinjections fail to elevate 'liking' (thus helping to identify the location of anatomical boundaries).

The results of such studies reveal a network of several brain hedonic hotspots, distributed as a chain of 'liking'-enhancing islands of brain tissue across several deep structures of the brain. The network of separate but interconnected hedonic hotspots acts together as a coordinated whole to amplify core pleasure reactions. Activating one recruits the others as a system (Smith et al. 2011). Each brain hotspot may be merely a cubic-millimeter or so in volume in the rodent brain (and would be expected to be a cubic-centimeter or so in you, if proportional to the larger human volume of whole brain). The small size of each anatomical hotspot indicates a surprisingly localized concentration of sufficient-cause mechanisms for generating an intense pleasure in the brain. The network properties reveal a fragile substrate for pleasure enhancement that requires unanimity across the several parts in order to elevate hedonic 'liking' (Pecina 2008; Pecina and Smith 2010; Smith et al. 2011; Smith et al. 2010).

One major hotspot has been found in the nucleus accumbens, a brain structure at the bottom front of the brain, specifically in its medial shell region near the center of the structure. Other hotspots have been found further back in the brain. For example, a very important hedonic hotspot lies in the ventral pallidum, which is near the hypothalamus near the very bottom center of the forebrain and receives most outputs from the nucleus accumbens. Still other hotspots may be found in more distant parts of the rodent brain, possibly as far front as limbic regions of prefrontal cortex, and almost certainly as far back as deep brainstem regions including the parabrachial nucleus in the top of the pons (Figure 3).

Analogous to scattered islands that form a single archipelago, the network of distributed hedonic hotspots forms a functional integrated circuit, which obeys control rules that are largely hierarchical and organized into brain levels (Aldridge et al. 1993; 
Berridge and Fentress 1986; Grill and Norgren 1978; Peciña et al. 2006). At the highest levels, the hotspot network may function as a more democratic heterarchy, in which unanimity of positive votes across hotspots is required in order to generate a greater pleasure. For example, any successful enhancement that starts in one hotspot involves recruiting neuronal activation across other hotspots simultaneously, to create a network of several that all vote 'yes' together for more pleasure (Smith et al. 2011). Conversely, a pleasure enhancement initiated by opioid activation of one hotspot can be vetoed by an opposite vote of 'no' from another hotspot where opioid signals are suppressed. Such findings reveal the need for unanimity across hotspots in order for a greater pleasure to be produced, and the potential fragility of hedonic enhancement if any hotspot defects (Smith and Berridge 2007; Smith et al. 2010).

But all of these findings on brain pleasure generators are focused on making pleasures nicer than usual. Neurochemical activation of hedonic hotspots creates a brain wellspring for intense pleasure when candidate sensations are encountered, generating high hedonic peaks of sensory pleasure.

Yet well-being is a more continuous state of hedonic normalcy, in which pleasures are not tied to any particular sensation but rather are frequent or sustained. What in the brain is required for creating the daily continual level of a normal pleasure gloss? It turns out that only some of the hotspots able to amplify pleasure are also necessary for maintaining normal hedonic levels of 'liking' to pleasant sensations. In both the clinical literature and in our experiments, normal core 'liking' reactions to pleasure are relatively difficult to abolish absolutely by any single event, condition, brain lesion or drug (Bruno et al. 2011; Pecina 2008; Pecina and Smith 2010; Smith et al. 2010). Resilience of brain circuits for normal baseline pleasures may be very good in evolutionary terms. Hedonic resilience may also be related to why many people can eventually regain a reasonably happy state even after catastrophic events (Diener et al. 2006; Gilbert 2006; Kahneman 1999). As an example, even people in the most extreme situations, such as in suffering the near-total paralysis of locked-in syndrome may remain happy (Bruno et al. 2011). Locked-in syndrome is a brain condition, typically caused by a small stroke-induced lesion in the brainstem lower pons that destroys movement pathways, which leaves the person fully aware and cognitively intact but completely paralyzed to the extent of being able only to make slight movements of an eye or eyelid. With an interpreter to help them pick alphabet letters one at a time, a locked-in patient can blink or move an eye at a chosen letter to form words and communicate. Yet in the face of even this devastating degree of paralysis, locked-in patients may often still be happy. A recent study found that $72 \%$ of locked-in respondents did report themselves to be moderately happy. The average response of this happy yet massively incapacitated group was +3 out of a hedonic scale from -5 to +5 , where +3 corresponded to 'very well' (between $+2=$ 'well', and $+4=$ "almost as well at the best period in my life prior to having locked-in syndrome"). The remaining $28 \%$ of locked-in respondents, who were much more likely to also be experiencing pain, reported themselves to be unhappy at -4 , but even this corresponded only to "almost as bad as the worst period in my life before locked-in syndrome" (and not quite as bad as $-5=$ "as bad as the worst period in my life before"); only 7\% wished for euthanasia (Bruno et al. 2011). Hedonic resilience can apparently often persist with seemingly little to go on, still generated by hedonic circuits within the person. 
Those few hedonic hotspots in which damage does destroy normal pleasure might be particularly important to hedonia in happy people. The most crucial hotspot for normal pleasures known so far is the one in the ventral pallidum. The ventral pallidum hotspot is the only brain location where lesion damage has been found in our lab studies to eliminate normal sensory pleasure, and so convert sweetness from a nice into a nasty experience (Pecina 2008; Pecina and Smith 2010; Smith et al. 2010). This site is still preserved in locked-in patients, perhaps contributing to their remaining wellbeing. Damage to the ventral pallidum brain site abolishes hedonic 'liking' reactions to sweetness and replaces them instead with disgust or 'disliking' reactions (e.g., gapes) as though the sweet taste had turned bitter (Berridge et al. 2010; Cromwell and Berridge 1993; Smith et al. 2010). The ventral pallidum is the chief recipient of output from the nucleus accumbens and part of a corticolimbic circuit that extends from prefrontal cortex to nucleus accumbens to ventral pallidum, which then loops up via thalamus to begin the circuit all over again in prefrontal cortex (Smith et al 2010).

An important question is how similar the ventral pallidum role in pleasure might be in humans compared to in rodents. Currently we do not have much available data on the hedonic consequences of human hotspot damage, because a human stroke or tumor lesion rarely damages the ventral pallidum on both sides of the brain without also damaging hypothalamus and related structures in between. That produces incapacitation so severe that pleasure no longer can be specifically assessed. Yet, in a rare human case report of a brain lesion that did rather selectively damage the ventral pallidal region on both sides without much else, positive affect and craving for previouslyaddictive rewards was reported to be much reduced (Miller et al. 2006). The patient's brain had incurred damage to ventral pallidum (and nearby medial globus pallidus) due to oxygen starvation when the patient stopped breathing during an enormous drug overdose (Miller et al. 2006). Afterwards the pallidal-lesion patient reported that his feelings became dominated by depression, hopelessness, guilt, and anhedonia. Even formerly craved and hedonic sensations like drinking alcohol lost their feelings of pleasure for him, and he no longer craved the many drugs of abuse that he had previously avidly consumed. Even this lesion probably did not fully destroy his ventral pallidum, and perhaps this is why he was not as strongly seized by disgust as a rat would be if it had complete lesions of the ventral pallidum hotspot. Instead, the patient still continued to eat and drink normally after his lesion, and even gained weight. But his apparent dramatic decline in hedonic well-being suggests an impairment in normal pleasure, and helps confirm a continuity between the ventral pallidum hotspot and human hedonia. We have also encountered anecdotal evidence that in some patients with pallidotomies (of nearby globus pallidus, just above and behind the human ventral pallidum) for Parkinson's patients, this led to severely flattened affect or anhedonia (Aziz, personal communication). The striking restriction of brain substrates where damage converts 'liking' to 'disliking' seems a testimonial to the robustness of the brain's capacity for a basic pleasure reaction (Smith et al. 2010), and also perhaps an insight into what pathological mechanisms result in true anhedonia.

\section{Additional pleasure codes in the brain}

The occurrence of pleasure is coded by neural activity in many additional forebrain sites beyond the hotspots mentioned above, including in amygdala and in the cortex: 
especially prefrontal cortical regions such as orbitofrontal cortex, anterior cingulate cortex, and insular cortex, (Aldridge and Berridge 2010; Grabenhorst and Rolls 2011; Kringelbach 2010; Leknes and Tracey 2010; Lundy 2008; Salimpoor et al. 2011; Skov 2010; Tindell et al. 2006; Veldhuizen et al. 2010; Vuust and Kringelbach 2010) (Figure $3)$.

But not all brain structures that code for pleasure actually help to cause it. Although correlated neuroimaging activations are sometimes viewed as implying causation, there remains a logical difference between coding and causing. Evidence indicates that the brain often organizes these differently. Coding of pleasure in the brain can reflect not only pleasure causation but also the neural consequences of pleasure: brain activity that results from pleasure enhancement but causes another function, such as cognition or learning. This implies that some brain activity may both cause and code pleasure reactions, whereas others do not cause pleasure but may code it. Instead those other activations cause different psychological or behavioral processes as consequences to the pleasure, such as attending to it, learning about it, or thinking about it. Neural coding is inferred in practice by measuring brain activity correlated to a pleasure, using techniques such as PET, fMRI and MEG neuroimaging in humans, or electrophysiological or neurochemical activation measures in animals presented with a rewarding stimulus (Figure 3,4). Causation is generally inferred on the basis of a change in pleasure caused by a brain manipulation such as lesion or stimulation.

As a general rule, we suggest that brains operate by the principle of 'many more codes than causes' for pleasure. In part, the greater number of hedonic coding sites results from the tendency of signals to spread beyond their source, as well as from the massive need for brain systems to translate pleasure signals into many other psychological functions, such as learning and memory, cognitive representations, decisions, action, and consciousness.

Code-but-not-cause systems might nonetheless be reliable indicators that a pleasant event is occurring, because they must take pleasure signals as inputs to achieve other component processes in reward and related psychological functions. We distinguish here between the cognitive representations and memories of reward (reward learning) and the motivational value appraisals or decisions (reward wanting). For example, parts of the prefrontal cortex regions sensitively code reward and hedonic impact, as described below. Yet damage to ventromedial region of prefrontal cortex may impair the cognitive use of emotional reactions without necessarily impairing the capacity to experience the hedonic impact of those emotional reactions (Bechara et al. 1997; Damasio 1999; Damasio 2004; Kringelbach 2005). The difference between coding and causing poses challenges to interpretation of brain activations. Still, the coding of pleasure is important to identify, whether the brain activation reflects cause or consequence. So what brain structures most specifically code pleasure?

\section{Cortical cognition and pleasure}

In humans, evidence suggests that pleasure encoding may reach an apex of cortical localization in a subregion of orbitofrontal cortex: this hedonic-coding site is placed in the mid-anterior and roughly mid-lateral zone of the orbitofrontal region (Figure 3,4) (Kringelbach 2005). In the mid-anterior zone of orbitofrontal cortex, activation revealed by neuroimaging in people particularly correlates strongly to their subjective 


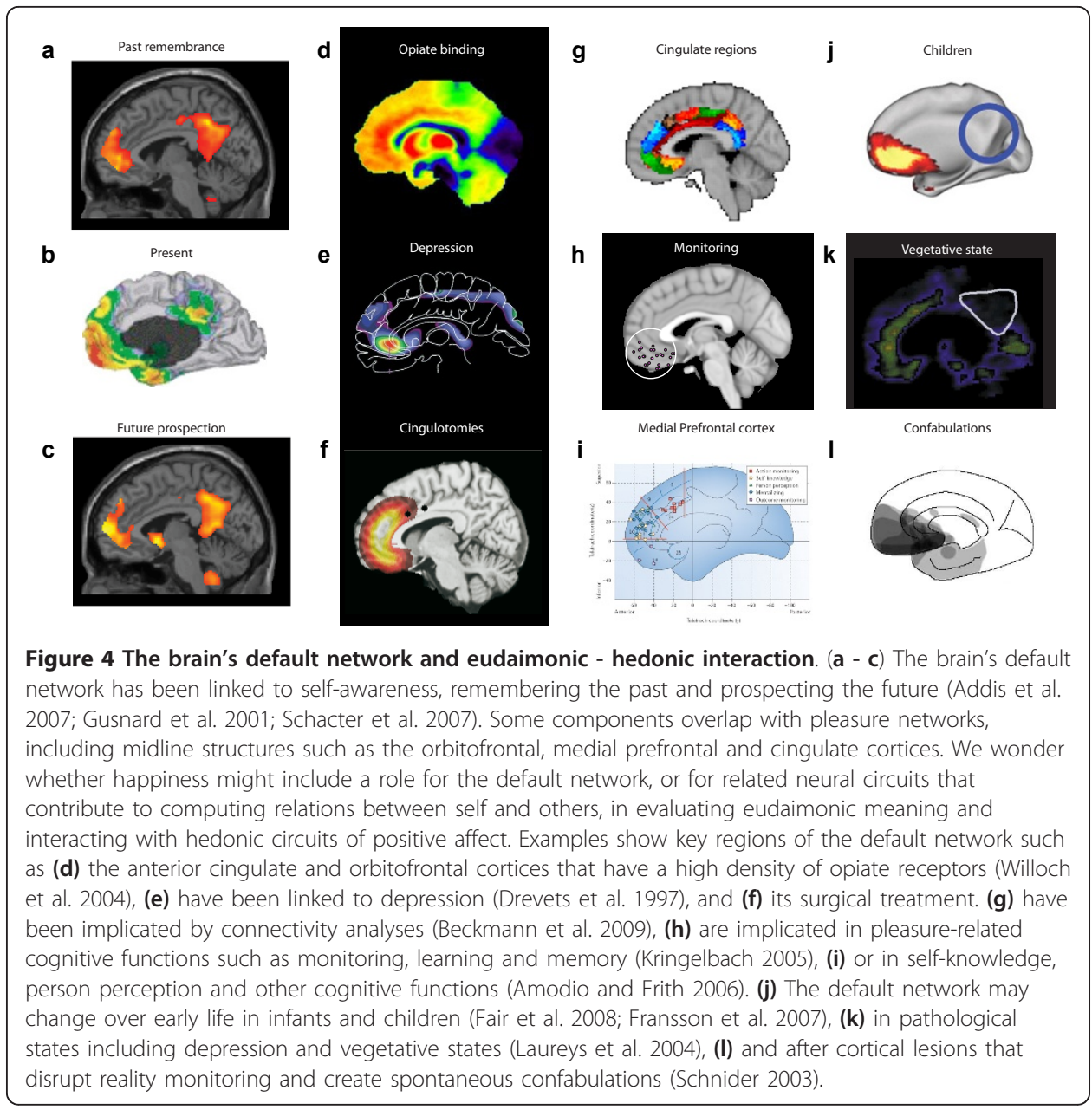

pleasantness ratings of food varieties - and to other pleasures such as sexual orgasms, drugs, chocolate, and music (Geogiadis and Kortekaas 2010; Kringelbach and Berridge 2010; Leknes and Tracey 2010; Veldhuizen et al. 2010; Vuust and Kringelbach 2010). Most importantly, activity in this special mid-anterior zone of orbitofrontal cortex selectively tracks changes in subjective pleasure of a sensation even when other aspects of the same sensation remain unchanged: such as a decline in palatability when the reward value of one food was reduced by eating it to satiety (while pleasantness and orbitofrontal activation remained high to another food) (Kringelbach 2005; Kringelbach et al. 2003). The mid-anterior subregion of orbitofrontal cortex is thus a prime candidate for the coding of subjective experience of pleasure (Kringelbach 2005).

Another potential coding site for positive hedonics in orbitofrontal cortex is a different zone along the medial edge. The medial orbitofrontal edge has activity related to the positive valence of affective events (Kringelbach 2010; Kringelbach and Rolls 2004), contrasted to lateral orbitofrontal zones that have been suggested to code unpleasant events (although lateral activity may reflect a signal to escape the situation, rather than displeasure per se) (Kringelbach 2010; Kringelbach and Rolls 2004). This medial-lateral hedonic gradient in orbitofrontal cortex interacts with an abstraction-concreteness gradient in the posterior-anterior dimension, so that more complex or abstract reinforcers (such as monetary gain and loss) are represented more anteriorly in the orbitofrontal 
cortex than less complex sensory rewards that activate posterior zones (such as taste). The medial region that codes pleasant sensations does not, however, appear to change its activity with reinforcer devaluation as effectively as the mid-anterior subregion that best codes hedonics, and so the medial region may not reflect the full dynamics of pleasure.

A malfunction of these hedonic mechanisms in the orbitofrontal cortex could contribute to the profound changes in eating habits (escalating desire for sweet food coupled with reduced satiety) that are often followed by enormous weight gain in patients with frontotemporal dementia. This progressive neurodegenerative disorder is associated with major and pervasive behavioral changes in personality and social conduct resembling those produced by orbitofrontal lesions (although it should be noted that more focal lesions to the orbitofrontal cortex have not to date been associated with obesity) (Rahman et al. 1999). It has become clear recently that the orbitofrontal cortex also has an important role in emotional disorders such as depression and addiction (Kringelbach 2005).

The proposed link to subjective hedonic processing might make the orbitofrontal cortex an important gateway for neuroscientific analyses of human subjective conscious experience. Some have even suggested that the orbitofrontal and anterior cingulate cortices together could be viewed as part of a global workspace for access to consciousness with the specific role of evaluating the affective valence of stimuli (Dehaene et al. 1998; Kringelbach and Berridge 2010). In this context, it is interesting that the medial parts of the orbitofrontal are part of a proposed network for the baseline activity of the human brain at rest (Gusnard et al. 2001), as this would place the orbitofrontal cortex as a key node in the network subserving consciousness. This could potentially explain why all our subjective experiences have an emotional tone and perhaps even why we have conscious pleasure.

Beyond orbitofrontal cortex, other cortical regions implicated in coding for pleasant stimuli include parts of the mid-insular (Craig 2009) and anterior cingulate cortices (Veldhuizen et al. 2010). As yet, however, it is not as clear as for the orbitofrontal cortex whether those regions specifically code pleasure or only emotion more generally (Feldman Barrett and Wager 2006). A related suggestion has emerged that the frontal left hemisphere plays a special lateralized role in positive affect more than the right hemisphere (Davidson 2004). Most specifically related to well-being, resting EEG activity in left prefrontal cortex has been reported to higher in individuals with greater eudaimonic and hedonic well-being (Urry et al. 2004). How to reconcile left-positive findings with many other findings of bilateral activity in orbitofrontal and related cortical regions during hedonic processing remains an ongoing puzzle.

\section{Cortical causation of human pleasure?}

Despite the evidence above for hedonic coding, however, it still remains unknown if even the mid-anterior pleasure-coding site of orbitofrontal cortex actually causes a positive pleasure state. It would be of considerable interest to investigate whether any of these sub-regions of the orbitofrontal cortex are necessary or sufficient causes of pleasure, or alternatively whether their role is restricted to cognitive elaboration of value, and translation of hedonic affect into goal-directed plans. 
One way of investigating this causation question would be to ask whether the orbitofrontal cortex is actually required for normal pleasure reactions or conscious feelings. Only scattered data are available, primarily from historical and case study sources. Prefrontal lobotomies were performed on thousands of human patients in the 1950s, and may provide some insights (Damasio 1999; Valenstein 1986). If orbitofrontal or other prefrontal areas are necessary for basic 'liking' reactions, these lobotomy patients should no longer have been able to feel pleasure. Yet perhaps surprisingly from this perspective, prefrontal lobotomy may not produce a catastrophic loss of pleasure feelings as far as one can tell from the available literature. Although many subtle emotional deficits occur in how patients describe or act upon their emotions after damage to prefrontal cortex the capacity for basic 'liking' reactions appeared to remain intact. Lobotomy patients were by no means oblivious to the pleasures of food, sex or other rewards.

Modern analyses of more focal prefrontal lesions report deficits in cognitive-emotional processing of decisions of human patients, similarly do not indicate a total loss of the capacity for pleasures (Bechara et al. 2000; Damasio 1999; Damasio 2004; Hornak et al. 2003). Decisions are often profoundly imbalanced in such patients but pleasures remain relatively normal. Overall, mood effects of cortical lesions are mixed and generally not hedonically devastating: although apathy and lack of affect is sometimes reported after to the dorsomedial prefrontal cortex, the nearly opposite symptoms of euphoria, impulsiveness, and general emotional disinhibition may be sometimes reported after damage to the ventromedial prefrontal and orbitofrontal cortex (Tucker et al. 1995). For example, Hornak and colleagues reported that after damage to the ventromedial prefrontal cortex and anterior cingulate cortex, increases in emotions such as happiness and anger were reported twice as often as decreases in emotion (typically of anger and fear when decreases occurred) (Hornak et al. 2003). Similarly, modern patients with orbitofrontal damage hedonic manifestations of good humor and self-satisfaction even in socially inappropriate situations, such as when teasing a stranger (Beer et al. 2003). Thus positive hedonia does not seem abolished by medial prefrontal or orbitofrontal cortex lesions, no matter what deficits in judgment and decision making do result. Such considerations suggest that orbitofrontal cortex might be more important to translating hedonic information into cognitive representations and decisions than to generating a core 'liking' reaction to pleasant events (Burke et al. 2010; Dickinson and Balleine 2010).

Similar reservations about whether pleasure is truly lost might also apply to certain types of clinical so-called 'anhedonia'. Anhedonia means loss of pleasure, which is often reported to result either from disruption of cortical activity patterns in orbitofrontal, insular, and cingulate regions of limbic cortex, or from depression or schizophrenia, or to occur following loss of dopamine in Parkinson's disease. Yet on closer inspection none of these may actually entail a true loss of capacity for all pleasures; sensory pleasures especially may persist quite intact, (Barch and Dowd 2010; Keedwell et al. 2005; Mitterschiffthaler et al. 2003; Sienkiewicz-Jarosz et al. 2005; Treadway and Zald 2011). For example, most anhedonic patients with schizophrenia or depression still give essentially normal hedonic ratings to the taste of sucrose (even if they have slight intensity impairments) (Berlin et al. 1998). Instead, the person retains core pleasures yet no longer seems to cognitively value those pleasures in their life as they once 
did. The sub-components of pleasure means that clinical anhedonia may be the outcome of a rather complex breakdown of cognitive construal about underlying wanting, liking and learning processes, rather than a simple loss of 'liked' pleasures themselves (Figure 5). It would be valuable to gain more information on the pleasure capacities of patients diagnosed with clinical anhedonia.

Such evidence leads us to suggest that that the human prefrontal cortex might not actually be needed to cause pleasure, or at least not for basic pleasures. It is possible that the main role of the prefrontal cortex in pleasure is to act as the interface of higher order processing such as consciousness and attention to the non-conscious pleasure generators in primarily sub-cortical regions (Izard 2007; Kringelbach 2010; Panksepp 2007; Smith et al. 2010).

At its extreme, this position might view hedonic reactions as arising from subcortical structures even when the subcortical brain is on its own and unable to interact with neocortex. Some further evidence from humans, as well as much from animals, supports a subcortical emphasis for pleasure generation. For example, Shewmon et al. described several hydranencephalic cases in children, including a 6-year old boy with congenital "absence of cerebral tissue rostral to the thalamus, except for small mesial temporal-lobe remnants" and a tissue-lined cyst (p. 364), who nevertheless "smiled when spoken to and giggled when played with. These human interactions were much more intense than, and qualitatively different from, his positive reactions to favorite

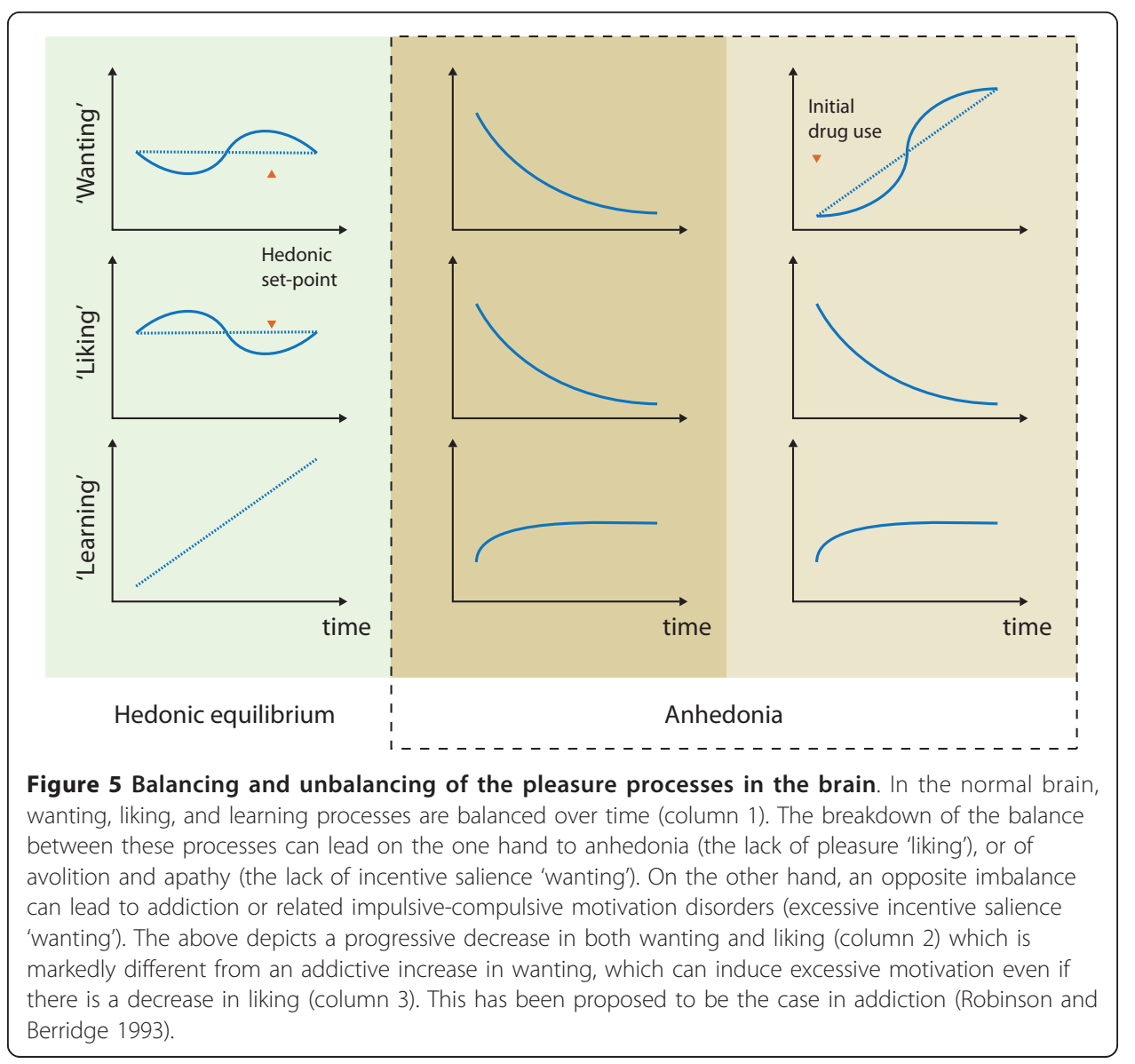


toys and music." (p. 366)(Shewmon et al. 1999). Similarly, Merker suggested that hydranencephalic children "express pleasure by smiling and laughter, and aversion by "fussing," arching of the back and crying (in many gradations), their faces being animated by these emotional states. A familiar adult can employ this responsiveness to build up play sequences predictably progressing from smiling, through giggling, to laughter and great excitement on the part of the child."(p. 79) (Merker 2007). Such cases of emotional reaction without (hardly any) cortex raise fascinating questions for future consideration about the relative roles of cortical regions versus subcortical structures in human pleasures. However, no matter what conclusion is reached regarding pleasure generation, there seems general consensus that neocortex is crucial to link affect with complex cognition and introspection about hedonic states.

\section{Controversial subcortical pleasure generators? Dopamine and electrical brain stimulation}

Several other particular limbic substrates, even subcortical ones, which were once thought to cause pleasure have now turned out not to do so after all. These include the mesolimbic dopamine system. They also may include so-called pleasure electrodes in related brain substrates. What is the hedonic status now of such brain substrates?

\section{Beyond pleasure for dopamine?}

Mesolimbic dopamine was long regarded as a pleasure neurotransmitter (Wise 1985), but now is increasingly thought by many neuroscientists to fail to live up to its pleasure label. One line of evidence against a pleasure-causing role is that mesolimbic dopamine neurons are not always reliably activated by pleasure as such, but instead by predictive, motivational, or attentional properties rather than hedonic properties of reward stimuli (Redgrave and Gurney 2006; Salamone et al. 2007; Schultz et al. 1997). Another line of evidence has been causal, such as observations that specific manipulation of dopamine either up or down always alters motivation 'wanting' for rewards but often fails to shift pleasure 'liking' reactions to the same rewards in either animals or humans (Berridge 2007; Leyton 2010; Smith et al. 2011). Such considerations can be combined with emerging evidence that dopamine signals are no more necessary or sufficient causes for learning about rewards (even if the signals often seem to code reward predictions) than for pleasure of rewards (Berridge 2007; Flagel et al. 2010; Palmiter 2007).

Taken together, such recent findings have led to suggestions that the primary role of mesolimbic dopamine in reward is to facilitate a psychological valuation process besides either learning or pleasure 'liking'. Suggestions have included motivational incentive salience, arousal, motivation, and memory consolidation (Barbano and Cador 2007; Berridge 2007; Niv et al. 2007; Robbins and Everitt 2007; Salamone et al. 2007). Thus the debate continues over the role of dopamine in reward. For now, however, we think it safe to sum up the consensus among affective neuroscientists by saying that brain mesolimbic dopamine is not, after all, primarily a pleasure neurotransmitter.

\section{Beyond Pleasure Electrodes?}

Similarly, so-called 'pleasure electrodes' in the brain for 50 years were supposed to tap directly into brain pleasure circuits (Olds 1956). However, we believe that many socalled 'pleasure electrodes' may actually have failed to truly cause significant pleasure 
at all. Instead we suggest most electrodes more exclusively activated only the 'wanting' component of reward (similar to mesolimbic dopamine stimulation; which indeed is typically activated by such electrodes). (Berridge 2003; Green et al. 2010; Kringelbach 2009; Kringelbach 2010; Kringelbach and Berridge 2010; Kringelbach et al. 2007; Smith et al. 2010). Such electrode activations may be sought out, or may stimulate seeking of external rewards (food, sex, gambling, shopping, etc.), yet need not be pleasant themselves.

The electrodes were originally discovered when implanted into deep brain sites that rats would work to stimulate (Olds and Milner 1954). For example, rats readily press a lever to stimulate brain electrodes in structures such as lateral hypothalamus, septum, nucleus accumbens or the medial forebrain bundle that carries dopamine fibers (Olds and Milner 1954; Shizgal et al. 2001). In rats, when the same electrodes are simply turned on freely without making the individual work for it, the electrode stimulation often also motivates the animals to eat, drink, engage in sex, etc. (Hoebel 1988; Valenstein and Cox 1970). However, even if electrodes make rats 'want' to eat food more voraciously, the same electrodes still fail to make rats 'like' the food more hedonically (Berridge and Valenstein 1991). This demonstrates dissociation between 'wanting' and 'liking' a reward, here induced by electrode stimulation.

In humans, famous cases of intense 'pleasure electrodes' soon followed the original discovery and are cited by many textbooks (Heath 1972). But when those cases are scrutinized more closely for pleasure, we think the conclusion emerges that most electrodes did not really cause much sensory pleasure after all, not even in the most famous cases (Berridge 2003; Smith et al. 2010). For example, take the much cited case of "B-19", a young man implanted with stimulation electrodes in septum/accumbens region by Heath and colleagues during the 1960s (Heath 1972). B-19 voraciously selfstimulated his electrode over a thousand times in a single session, and protested when the stimulation button was taken away. In addition, his electrode was claimed by Heath to cause "feelings of pleasure, alertness, and warmth (goodwill); he had feelings of sexual arousal and described a compulsion to masturbate" (p. 6, Heath 1972).

But did B-19's electrode really cause a pleasure sensation? It is not actually so clear from data in the reports, and B-19 was never quoted as saying it did; not even an exclamation or anything like "Oh - that feels nice!" Instead B-19's electrode stimulation evoked desire to stimulate again and strong sexual arousal - while never producing sexual orgasm or clear evidence of actual pleasure sensation. Similarly, the stimulation never served as a substitute for sexual acts. What it did instead was to make him want to engage in more sexual acts; just as the stimulation made him want to press the button more.

Another example comes from a woman implanted with a deep brain electrode decades later by a different team (Portenoy et al. 1986). Given a button box to control the electrode, she compulsively stimulated her electrode at home: "At its most frequent, the patient self-stimulated throughout the day, neglecting personal hygiene and family commitments" (p. 279) (Portenoy et al. 1986). When her electrode was stimulated in the clinic, it produced a strong desire to drink liquids, and some erotic feelings, as well as a continuing desire to stimulate again. However, “... though sexual arousal was prominent, no orgasm occurred” (p. 279, Portenoy et al. 1986). This seems rather similar to the case of B-19: "She described erotic sensations often intermixed with an 
undercurrent of anxiety. She also noted extreme thirst, drinking copiously during the session, and alternating generalized hot and cold sensations" (p. 282, Portenoy et al. 1986). Clearly this woman felt a mixture of subjective feelings, but the description's emphasis is on aversive thirst and anxiety - without evidence of distinct pleasure sensations.

Deep brain stimulation has resurged as a therapeutic technique in the past 10 years, though now it typically is delivered in a different way. In contemporary brain stimulation, pulses of electrode stimulation are typically programmed by computer and delivered independently of any action by the patient rather than requiring a patient to press a button. In many cases the patient may not have any control at all over the stimulation pattern (though some still do). Such programmed pulses of stimulation are being applied to pathological moods involving depression or obsessive-compulsive disorder and to movement disorders such as Parkinson's disease (Green et al. 2010; Haber and Brucker 2009; Kringelbach et al. 2007; Lozano et al. 2008; Schlaepfer et al. 2007; Voon et al. 2006; Wichmann and DeLong 2006). The target sites of such deep brain electrodes include the nucleus accumbens and the subthalamic nucleus (Schlaepfer et al. 2008), the subgenual cingulate cortex, and fibers descending from prefrontal cortex through the internal capsule (Lozano et al. 2008). In addition, lesions of the posterior part of the anterior cingulate cortex have been used for the treatment of depression with some success (Steele et al. 2008).

In some cases, the deep electrode stimulation appears helpful to the original pathological condition, and in quite a number of instances there are positive changes in motivation or attitude. But do such newer electrodes actually deliver pleasure or hedonic well-being? Let's take a closer look.

There are a few apparently promising cases for hedonic generation, at least at first glance, but even these we think generally do not present strong evidence for pleasure on closer scrutiny. For example, in one case, intense 'mirthful laughter' was generated in a man with Parkinson's when his subthalamic nucleus was stimulated by an electrode. The subthalamic nucleus is connected to mesolimbic circuits of mood as well as corticostriatal circuits of movement, and so motivational effects can accompany electrode activations intended to help control tremor or movement problems (Krack et al. 2001). The man "initially found the laughter amusing" (p. 869), seeming to provide a candidate for direct activation of a happier mood state. His elevation in amusement and mood persisted while the electrode remained on. However, it is worth noting that several doctors in the room also 'fell into a hilaric state' during his electrode activation though their brains received no stimulation. Laughter can be contagious, and it might be wondered whether some of the patient's own laughter might have reflected something other than direct activation of a pleasurable mood of laughing hilarity. Doubts grow further on noting what happened next: as the electrode stimulation continued further, the man reported that "the laughter eventually became annoying and uncomfortable". Finally, the stimulation and laughter "became unpleasant with time and he asked whether we could stop making him laugh" (p.870) (Krack et al. 2001). It seems his laughter was being evoked as a complex pattern of emotional action, which could induce either a contagious positive mood or an aversive mood that was actually unpleasant, rather than simply reflecting a pleasantly funny state.

Another example comes from a woman with a stimulating electrode implanted in the same subthalamic nucleus circuit: she experienced manic episodes of intense 
motivation when her electrode was on. She became energized, finding herself able to do lots of things and sleep only 3 or 4 hours at night (Herzog et al. 2003). She developed a host of new positive affections and desires in life when her electrode was being stimulated. For example she was described by her physicians as becoming possessed by feelings of being "in love with two neurologists, and tried to embrace and kiss people" and engaging in binges of "unrestrained buying of clothes" to the extent that her family wanted to take away her credit card. Yet again, this was not a purely happy state of exhilaration even for the woman. She was also described, while her brain was stimulated, as being "suspicious, tense and hostile. She developed a "delusion that her sons were conspiring against her, and she said that they tried to get her money by threat of force" (all p.1383) (Herzog et al. 2003).

Of course, our conclusion that such brain electrodes failed to cause real pleasure in these cases does not mean that no electrode ever did, nor still less, that future pleasure electrodes never will. One of us (MLK) has witnessed dramatic pain relief, at least, in chronic pain patients when deep brain stimulation was turned on (Kringelbach et al. 2009), an effect which is perhaps caused by the rebalancing of pathological oscillations in brain networks (Kringelbach et al. 2010). Pain relief is of course important to wellbeing and some would view pain relief as almost equivalent to pleasure and happiness. That view was captured for example in William James' slightly tongue-in-cheek quip expressed in a letter to a correspondent after he finished a strenuous set of public lectures: "Happiness, I have lately discovered, is no positive feeling, but a negative condition of freedom from a number of restrictive sensations of which our organism usually seems the seat. When they are wiped out, the clearness and cleanness of the contrast is happiness. This is why anaesthetics make us so happy. But don't you take to drink on that account." (p.158) (James 1920).

Still, we believe that even William James at other moments would probably have agreed that, however valuable relief from pain is as contrast from preceding suffering, the absence of pain by itself is not tantamount to a positive pleasure. Absence of pain alone cannot bring well-being or happiness. Pleasure and well-being have distinct psychological features and require their own hedonic neural activations. And pleasure is exactly what the electrode stimulations seem to lack as best we can tell after reviewing the available cases (Green et al. 2010; Kringelbach et al. 2007; Smith et al. 2010). At least, we surmise that the most prototypical and classic cases of 'pleasure electrodes' from the past are open to grave doubt, and most recent cases of programmed deep brain stimulation similarly seem to fail to induce true pleasure or well-being. Continued close scrutiny of deep brain stimulation electrodes as future studies emerge will certainly be needed to answer the question: do any electrodes really cause pleasure?

\section{Discussion}

\section{Incentive salience as potential explanation for dopamine and electrodes}

What could such reward electrodes or mesolimbic dopamine activations be doing, if not causing pleasure? One possible explanation is that they promote 'wanting' without 'liking'. We suggest those electrode activations and mesolimbic dopamine in general momentarily enhance motivational value in the form of incentive salience attribution to surroundings and stimuli perceived or imagined at that moment. The incentive salience becomes permanently attached to those particular stimuli to make them 'wanted'. 
For the original 'pleasure electrodes', incentive salience would be attributed especially to the act of stimulating the electrode via pressing the button, and to the stimuli that surround that act. If the electrodes caused 'wanting', a person might well describe a sudden feeling that life was suddenly more attractive, desirable, and compelling to pursue. If it caused 'wanting' attribution to the button and the act of pressing it, people might well 'want' to activate their electrode again, even if it produced no pleasure sensation. Attribution of incentive salience to nearby people might help the individual to 'fall in love', and attribution to cues that are nearby or that signify individually-favorite incentives could lead to binges of compulsive shopping, gambling, etc. All that could be mere incentive salience 'wanting' - without hedonic 'liking' (Figure 5). It would be possible in that case to 'want' to press the electrode again, or to 'want' another incentive quite impulsively, without ever gaining significant pleasure, or even necessarily having a clear expectation of gaining pleasure from the electrode or the incentive target. Similar 'wanting' interpretations have been applied more generally to the role of mesolimbic dopamine in reward (Berridge 2007; Berridge and Robinson 1998).

Something similar may also happen in drug addicts due to a phenomenon called drug-induced sensitization of brain mesolimbic systems. This neural change can induce hyper-reactivity to particular incentives, called incentive-sensitization, and may well last years. (Robinson and Berridge 1993; Robinson and Berridge 2003). Considerable evidence has recently emerged to bear on such excesses of desire (Boileau et al. 2006; Camerer 2006; Evans et al. 2006; Finlayson et al. 2007; Lawrence et al. 2003; Leyton 2010; Robinson and Berridge 2003; Wiers et al. 2007; Wiers and Stacy 2006).

\section{Bridging pleasure to meaning}

It is interesting to note that all brain structures discussed above or being targeted for brain-based treatments of pathological mood disorders today either have close links with the hedonic network we have considered (e.g., orbitofrontal cortex, nucleus accumbens and ventral pallidum, etc.) or belong to what has been termed the brain's default network which changes over early development (e.g., additional regions of prefrontal cortex, or of cingulate cortex, temporal cortex, and parietal cortex) (Fair et al. 2008; Fransson et al. 2007) (Figure 4).

Mention of the default network brings us back to the topic of eudaimonic happiness, and to potential interactions of hedonic brain circuits with circuits that assess meaningful relationships of self to social others. The default network is a steady state circuit of the brain which becomes perturbed during cognitive tasks (Gusnard et al. 2001). Most pertinent here is an emerging literature that has proposed the default network to carry representations of self (Lou et al. 1999), internal modes of cognition (Buckner et al. 2008), and perhaps even states of consciousness (Laureys et al. 2004). Such functions might well be important to higher pleasures as well as meaningful aspects of happiness.

Although highly speculative, we wonder whether the default network might deserve further consideration for a role in connecting eudaimonic and hedonic happiness. At least, key regions of the frontal default network overlap with the hedonic network discussed above, such as the anterior cingulate and orbitofrontal cortices (Beckmann et al. 2009; Kringelbach and Rolls 2004; Steele et al. 2008), and have a relatively high density of opiate receptors (Henriksen and Willoch 2008). Eudaimonic wellbeing may be 
correlated with activity in the anterior cingulate and in left prefrontal cortex, perhaps though the ability to suppress negative emotions (Urry et al. 2004; Urry et al. 2006; van Reekum et al. 2007). Activity changes in the frontal default network, such as in the subgenual cingulate and orbitofrontal cortices, correlate to pathological changes in subjective hedonic experience, such as in depressed patients (Davidson et al. 2002).

Pathological self-representations by the frontal default network could also provide a potential link between hedonic distortions of happiness that are accompanied by eudaimonic dissatisfaction, such as in cognitive rumination of depression (Addis et al. 2007; Gusnard et al. 2001; Schacter et al. 2007; Schnider 2003). Conversely, mindfulnessbased cognitive therapy for depression, which aims to disengage from dysphoria-activated depressogenic thinking might conceivably recruit default network circuitry to help mediate improvement in happiness via a linkage to hedonic circuitry (Teasdale et al. 2000).

Beyond the default network, other cortical networks have been proposed to correspond by direct activation with eudaimonic evaluations of self, relation to others, and with meaningful themes related to life satisfaction (Heller et al. 2009; Schacter et al. 2007). These include dorsolateral prefrontal, and other parietal and temporal cortex networks. In short, the default network and lateral cortical networks whose activation encodes evaluations of self and life meaning stand among the brain candidates for a substrate that might mediate eudaimonic appraisals. How these networks actually embody eudaimonia components, and how they link evaluations of life meaningfulness and satisfaction with pleasurable states of hedonia, remains a major puzzle for psychological neuroscience to unravel in the future.

\section{Conclusions}

While some progress has been made in understanding brain hedonics, it is important not to over-interpret. We do not yet have a neuroscience of happiness. We have merely aimed to sketch out the beginnings of a hedonic approach that may prove fruitful. Further, when all is done, one may still question our entire effort, based as it is largely on evidence from sensory pleasures. Some will demur that pleasure, our chief focus here, is irrelevant after all to true happiness. For many, this view might be well expressed by the words of John Stuart Mill, "It is better to be a human being dissatisfied than a pig satisfied; better to be Socrates dissatisfied than a fool satisfied." (Mill, Crisp and NetLibrary Inc. 1998)(p. 57). By the view expressed in this quotation, a life filled with the most intense pleasures of pigs or fools would never be enough for happiness because true happiness hinges on a superior kind of psychological or eudaimonic richness that is unique to the enlightened, though hedonically dissatisfied, Socrates (Mill himself, however, seemed to assent elsewhere that hedonic pleasure was important to happiness too).

At the opposite extreme, Sigmund Freud seemed to take a purely hedonic view of happiness, more likely to favor our endeavor. Freud wrote, in response to his own question concerning what people demand of life and wish to achieve in it, the reply "The answer to this can hardly be in doubt. They strive after happiness; they want to become happy and to remain so. This endeavor has two sides, a positive and a negative aim. It aims, on the one hand, at an absence of pain and displeasure, and, on the other, at the experiencing of strong feelings of pleasure" (Freud 1930)(p.76). Freud's answer 
equates hedonic pleasure with happiness. According to this view, the more pleasure you have (while avoiding displeasure), the happier you are. Modern psychologists tend to fall in between these poles. Yet relatively few today would deny that hedonic pleasure is at least relevant to a final state of well-being.

We do not pretend to see deeper into the nature of happiness than those thinkers of earlier times, but simply point again to the empirical convergence of hedonic and eudaimonic features together in most people who are actually happy. And we note in conclusion, that so far as positive affect contributes to happiness, then at least some progress has been made in understanding the neurobiology of pleasure in ways that might be relevant.

In finishing, we can imagine several possibilities to relate happiness to particular hedonic psychological processes discussed above. Thus, one way to conceive of hedonic happiness is as 'liking' without 'wanting. That is, a state of pleasure without disruptive desires, a state of contentment (Kringelbach and Berridge 2009). A different possibility is that moderate 'wanting', matched to positive 'liking', facilitates engagement with the world. A little incentive salience may add zest to the perception of life and perhaps even promote the construction of meaning, just as in some patients therapeutic deep brain stimulation may help lift the veil of depression by making life events more appealing. However, too much 'wanting' can readily spiral into maladaptive patterns such as addiction, and is a direct route to great unhappiness. Finally, all might agree that happiness springs not from any single component but from the interplay of higher pleasures, positive appraisals of life meaning and social connectedness, all combined and merged by interaction between the brain's default networks and pleasure networks. Achieving the right hedonic balance in such ways may be key to the brain's generation of positive well-being.

\section{Acknowledgements}

The authors' research has been supported by grants from the NIH (MH63644 and DA015188) to KCB, and from the TrygFonden Charitable Foundation, Braveheart Charity, Novo Nordisk Foundation to MLK. We thank Asma'u Mustapha and two anonymous reviewers for helpful comments on an earlier version of the manuscript. This essay was modified from recent articles by the authors.

\section{Author details}

${ }^{1}$ Department of Psychology, University of Michigan, Ann Arbor, USA ²Department of Psychiatry, Warneford Hospital, University of Oxford, Oxford, UK ${ }^{3}$ Centre for Functionally Integrative Neuroscience (CFIN), University of Aarhus, Aarhus, Denmark

Authors' contributions

The authors contributed equally to this work

Competing interests

The authors declare that they have no competing interests.

Received: 16 March 2011 Accepted: 24 October 2011 Published: 24 October 2011

References

Addis, DR, Wong, AT, Schacter, DL (2007). Remembering the past and imagining the future: Common and distinct neural substrates during event construction and elaboration. Neuropsychologia, 45, 1363-1377.

Aldridge, JW, \& Berridge, KC (2010). Neural coding of pleasure: "rose-tinted glasses" of the ventral pallidum. In Kringelbach, Berridge (Ed.), Pleasures of the brain (pp. 62-73). Oxford: Oxford University Press.

Aldridge, JW, Berridge, KC, Herman, M, Zimmer, L (1993). Neuronal coding of serial order: Syntax of grooming in the neostriatum. Psychological Science, 4, 391-395.

Amodio, DM, \& Frith, CD (2006). Meeting of minds: The medial frontal cortex and social cognition. Nat Rev Neurosci, 7 , $268-277$.

Aragona, BJ, Liu, Y, Yu, YJ, Curtis, JT, Detwiler, JM, Insel, TR, Wang, Z (2006). Nucleus accumbens dopamine differentially mediates the formation and maintenance of monogamous pair bonds. Nat Neurosci, 9, 133-139. 
Aristotle, (2009). The nicomachean ethics. Oxford, UK: Oxford University Press.

Barbano, MF, \& Cador, M (2007). Opioids for hedonic experience and dopamine to get ready for it. Psychopharmacology (Berl), 191, 497-506.

Barch, DM, \& Dowd, EC (2010). Goal representations and motivational drive in schizophrenia: The role of prefrontal-striatal interactions. Schizophr Bull, 36, 919-934.

Bechara, A, Damasio, H, Damasio, AR (2000). Emotion, decision making and the orbitofrontal cortex. Cereb Cortex, 10, 295-307.

Bechara, A, Damasio, H, Tranel, D, Damasio, AR (1997). Deciding advantageously before knowing the advantageous strategy. Science, 275, 1293-1295.

Beckmann, M, Johansen-Berg, H, Rushworth, MFS (2009). Connectivity-based parcellation of human cingulate cortex and its relation to functional specialization. J Neurosci, 29, 1175-1190.

Beer, JS, Heerey, EA, Keltner, D, Scabini, D, Knight, RT (2003). The regulatory function of self-conscious emotion: Insights from patients with orbitofrontal damage. J Pers Soc Psychol, 85, 594-604.

Berlin, I, Givry-Steiner, L, Lecrubier, Y, Puech, AJ (1998). Measures of anhedonia and hedonic responses to sucrose in depressive and schizophrenic patients in comparison with healthy subjects. Eur Psychiat, 13, 303-309.

Berridge, KC (2003). Pleasures of the brain. Brain Cogn, 52, 106-128.

Berridge, KC (2007). The debate over dopamine's role in reward: The case for incentive salience. Psychopharmacology (Berl), $191,391-431$.

Berridge, KC, \& Fentress, JC (1986). Contextual control of trigeminal sensorimotor function. J Neurosci, 6, 325-330.

Berridge, KC, Ho, CY, Richard, JM, DiFeliceantonio, AG (2010). The tempted brain eats: Pleasure and desire circuits in obesity and eating disorders. Brain Res, 1350, 43-64.

Berridge, KC, \& Kringelbach, ML (2008). Affective neuroscience of pleasure: Reward in humans and animals. Psychopharmacology (Berl), 199, 457-480.

Berridge, KC, \& Robinson, TE (1998). What is the role of dopamine in reward: Hedonic impact, reward learning, or incentive salience? Brain Res Rev, 28, 309-369.

Berridge, KC, Robinson, TE, Aldridge, JW (2009). Dissecting components of reward: 'liking', 'wanting', and learning. Curr Opin Pharmacol, 9, 65-73.

Berridge, KC, \& Schulkin, J (1989). Palatability shift of a salt-associated incentive during sodium depletion. Quarterly Journal of Experimental Psychology [b], 41, 121-138.

Berridge, KC, \& Valenstein, ES (1991). What psychological process mediates feeding evoked by electrical stimulation of the lateral hypothalamus? Behav Neurosci, 105, 3-14.

Boileau, I, Dagher, A, Leyton, M, Gunn, RN, Baker, GB, Diksic, M, Benkelfat, C (2006). Modeling sensitization to stimulants in humans: An [11c]raclopride/positron emission tomography study in healthy men. Arch Gen Psychiatry, 63, 1386-1395.

Bok, DC (2010). The politics of happiness: What government can learn from the new research on well-being. Princeton: Princeton University Press.

Bok, S (2010). Exploring happiness: From aristotle to brain science. New Haven [Conn.]: Yale University Press.

Britton, JC, Phan, KL, Taylor, SF, Welsh, RC, Berridge, KC, Liberzon, I (2006). Neural correlates of social and nonsocial emotions: An fmri study. Neuroimage, 31, 397-409.

Bruno, M-A, Bernheim, JL, Ledoux, D, Pellas, F, Demertzi, A, Laureys, S (2011). A survey on self-assessed well-being in a cohort of chronic locked-in syndrome patients: Happy majority, miserable minority. BMJ Open, 1, e000039.

Buckner, RL, Andrews-Hanna, JR, Schacter, DL (2008). The brain's default network: Anatomy, function, and relevance to disease. Ann N Y Acad Sci, 1124, 1-38.

Burke, KA, Miller, D, Schoenbaum, G (2010). Conditioned reinforcement and the specialized role of corticolimbic circuits in the pursuit of happiness and other more specific rewards. In Kringelbach, Berridge (Ed.), Pleasures of the brain (pp. 50-61). Oxford, U.K.: Oxford University Press.

Cabanac, M (2010). The dialectics of pleasure. In Kringelbach, Berridge (Ed.), Pleasures of the brain (pp. 113-124). Oxford, U.K.: Oxford University Press.

Camerer, CF (2006). Wanting, liking, and learning: Neuroscience and paternalism. Univ Chicag Law Rev, 73, 87-110.

Craig, AD (2009). How do you feel-now? The anterior insula and human awareness. Nat Rev Neurosci, 10, 59-70.

Cromwell, HC, \& Berridge, KC (1993). Where does damage lead to enhanced food aversion: The ventral pallidum/substantia innominata or lateral hypothalamus? Brain Res, 624, 1-10.

Damasio, AR (1999). The feeling of what happens: Body and emotion in the making of consciousness. 1st edition. New York: Harcourt Brace.

Damasio, AR (2004). Emotions and feelings: A neurobiological perspective. In Manstead, Frijda, Fischer (Ed.), Feelings and emotions: The amsterdam symposium (pp. 49-57). Cambridge, U.K.: Cambridge University Press.

Darwin, C (1872). The expression of the emotions in man and animals. London: J. Murray.

Davidson, RJ (2004). Well-being and affective style: Neural substrates and biobehavioural correlates. Philos Trans R Soc Lond B Biol Sci, 359, 1395-1411.

Davidson, RJ, Lewis, DA, Alloy, LB, Amaral, DG, Bush, G, Cohen, JD, Drevets, WC, Farah, MJ, Kagan, J, McClelland, JL, et al. (2002). Neural and behavioral substrates of mood and mood regulation. Biol Psychiatry, 52, 478-502.

Dehaene, S, Kerszberg, M, Changeux, JP (1998). A neuronal model of a global workspace in effortful cognitive tasks. Proc Natl Acad Sci USA, 95, 14529-14534.

Dickinson, A, \& Balleine, B (2010). Hedonics: The cognitive-motivational interface. In Kringelbach, Berridge (Ed.), Pleasures of the brain (pp. 74-84). Oxford, U.K.: Oxford University Press.

Diener, E, Kesebir, P, Lucas, R (2008). Benefits of accounts of well-being - for societies and for psychological science. Applied Psychol, 57, 37-53.

Diener, E, Lucas, RE, Scollon, CN (2006). Beyond the hedonic treadmill - revising the adaptation theory of well-being. Am Psychol, 61, 305-314.

Drevets, WC, Price, JL, Simpson, JR, Todd, RD, Reich, T, Vannier, M, Raichle, ME (1997). Subgenual prefrontal cortex abnormalities in mood disorders. Nature, 386, 824-827. 
Evans, AH, Pavese, N, Lawrence, AD, Tai, YF, Appel, S, Doder, M, Brooks, DJ, Lees, AJ, Piccini, P (2006). Compulsive drug use linked to sensitized ventral striatal dopamine transmission. Ann Neurol, 59, 852-858.

Everitt, BJ, Belin, D, Economidou, D, Pelloux, Y, Dalley, JW, Robbins, TW (2008). Neural mechanisms underlying the vulnerability to develop compulsive drug-seeking habits and addiction. Philos Trans R Soc Lond B Biol Sci, 363, 3125-3135.

Fair, DA, Cohen, AL, Dosenbach, NU, Church, JA, Miezin, FM, Barch, DM, Raichle, ME, Petersen, SE, Schlaggar, BL (2008). The maturing architecture of the brain's default network. Proc Natl Acad Sci USA, 105, 4028-4032.

Feldman Barrett, L, \& Wager, TD (2006). The structure of emotion: Evidence from neuroimaging studies. Curr Dir Psychol, 15, 79-83.

Finlayson, G, King, N, Blundell, JE (2007). Is it possible to dissociate 'liking' and 'wanting' for foods in humans? A novel experimental procedure. Physiol Behav, 90, 36-42.

Flagel, SB, Robinson, TE, Clark, JJ, Clinton, SM, Watson, SJ, Seeman, P, Phillips, PE, Akil, H (2010). An animal model of genetic vulnerability to behavioral disinhibition and responsiveness to reward-related cues: Implications for addiction. Neuropsychopharmacology, 35, 388-400.

Fransson, P, Skiold, B, Horsch, S, Nordell, A, Blennow, M, Lagercrantz, H, Aden, U (2007). Resting-state networks in the infant brain. Proc Natl Acad Sci USA, 104, 15531-15536.

Freud, S (1930). Civilization and its discontents. New York: Norton \& Co.

Frijda, N (2010). On the nature and function of pleasure. In Kringelbach, Berridge (Ed.), Pleasures of the brain (pp. 99-112). Oxford, U.K.: Oxford University Press.

Friston, K, \& Kiebel, S (2009). Predictive coding under the free-energy principle. Philos Trans R Soc Lond B Biol Sci, 364, $1211-1221$.

Frith, U, \& Frith, C (2010). The social brain: Allowing humans to boldly go where no other species has been. Philos Trans $R$ Soc Lond B Biol Sci, 365, 165-176.

Geogiadis, JR, \& Kortekaas, R (2010). The sweetest taboo: Functional neurobiology of human sexuality in relation to pleasure. In Kringelbach, Berridge (Ed.), Pleasures of the brain (pp. 178-201). Oxford, U.K: Oxford University Press.

Gilbert, DT (2006). Stumbling on happiness. New York: Alfred A. Knopf.

Gottfried, J (2010). Olfaction and its pleasures: Human neuroimaging perspectives. In Kringelbach, Berridge (Ed.), Pleasures of the brain (pp. 125-145). Oxford, U.K.: Oxford University Press.

Grabenhorst, F, \& Rolls, ET (2011). Value, pleasure and choice in the ventral prefrontal cortex. Trends Cog Sci, 15, 56-67.

Green, AL, Pereira, EA, Aziz, TZ (2010). Deep brain stimulation and pleasure. In Kringelbach, Berridge (Ed.), Pleasures of the brain (pp. 302-319). Oxford, U.K.: Oxford University Press.

Grill, HJ, Berridge, KC, Ganster, DJ (1984). Oral glucose is the prime elicitor of preabsorptive insulin secretion. Am J Physiol, 246, R88-95.

Grill, HJ, \& Norgren, R (1978). The taste reactivity test. I. Mimetic responses to gustatory stimuli in neurologically normal rats. Brain Res, 143, 263-279.

Grill, HJ, \& Norgren, R (1978). The taste reactivity test. li. Mimetic responses to gustatory stimuli in chronic thalamic and chronic decerebrate rats. Brain Res, 143, 281-297.

Gusnard, DA, Raichle, ME, Raichle, ME (2001). Searching for a baseline: Functional imaging and the resting human brain. Nat Rev Neurosci, 2, 685-694.

Haber, SN, \& Brucker, JL (2009). Cognitive and limbic circuits that are affected by deep brain stimulation. Front Biosci, 14, 1823-1834.

Harris, S, Kaplan, JT, Curiel, A, Bookheimer, SY, lacoboni, M, Cohen, MS (2009). The neural correlates of religious and nonreligious belief. PLOS ONE, 4, e7272.

Heath, RG (1972). Pleasure and brain activity in man. Deep and surface electroencephalograms during orgasm. J Nerv Mental Dis, 154, 3-18.

Heller, AS, Johnstone, T, Shackman, AJ, Light, SN, Peterson, MJ, Kolden, GG, Kalin, NH, Davidson, RJ (2009). Reduced capacity to sustain positive emotion in major depression reflects diminished maintenance of fronto-striatal brain activation. Proceedings of the National Academy of Sciences, 106, 22445-22450.

Henriksen, G, \& Willoch, F (2008). Imaging of opioid receptors in the central nervous system. Brain, 131, 1171-1196.

Herzog, J, Reiff, J, Krack, P, Witt, K, Schrader, B, Muller, D, Deuschl, G (2003). Manic episode with psychotic symptoms induced by subthalamic nucleus stimulation in a patient with parkinson's disease. Mov Disord, 18, 1382-1384.

Hoebel, BG (1988). Neuroscience and motivation: Pathways and peptides that define motivational systems. In Atkinson (Ed.), Stevens' handbook of experimental psychology. Volume 1. 2 edition. New York: John Wiley \& Sons.

Hornak, J, Bramham, J, Rolls, ET, Morris, RG, O'Doherty, J, Bullock, PR, Polkey, CE (2003). Changes in emotion after circumscribed surgical lesions of the orbitofrontal and cingulate cortices. Brain, 126, 1691-1712.

Izard, CE (2007). Basic emotions, natural kinds, emotion schemas, and a new paradigm. Perspect Psychol Sci, 2, 260-280.

James, W (1920). Letter on happiness to miss frances r. Morse (1901). In James (Ed.), Letters of william james. Volume 2. Boston: Atlantic Monthly Press.

Kahneman, D (1999). Assessments of individual well-being: A bottom-up approach. In Kahneman, Diener, Schwartz (Ed.), Well-being: The foundations of hedonic psychology. New York: Russel Sage Foundation.

Kahneman, D (1999). Objective happiness. In Kahneman, Diener, Schwarz (Ed.), Well-being: The foundations of hedonic psychology (pp. 3-25). New York: Russell Sage Foundation.

Keedwell, PA, Andrew, C, Williams, SC, Brammer, MJ, Phillips, ML (2005). The neural correlates of anhedonia in major depressive disorder. Biol Psychiatry, 58, 843-853.

Kelley, AE, \& Berridge, KC (2002). The neuroscience of natural rewards: Relevance to addictive drugs. J Neurosci, 22, 3306-3311.

King-Casas, B, Tomlin, D, Anen, C, Camerer, CF, Quartz, SR, Montague, PR (2005). Getting to know you: Reputation and trust in a two-person economic exchange. Science, 308, 78-83.

Komisaruk, BR, Whipple, B, Beyer, C (2010). Sexual pleasure. In Kringelbach, Berridge (Ed.), Pleasures of the brain (pp. 169-177). Oxford, U.K.: Oxford University Press.

Koob, GF, \& Volkow, ND (2010). Neurocircuitry of addiction. Neuropsychopharmacology, 35, 217-238.

Krack, P, Kumar, R, Ardouin, C, Dowsey, PL, McVicker, JM, Benabid, AL, Pollak, P (2001). Mirthful laughter induced by subthalamic nucleus stimulation. Movement Dis, 16, 867-875. 
Kringelbach, M, Lehtonen, A, Squire, S, Harvey, A, Craske, M, Holliday, I, Green, A, Aziz, T, Hansen, P, Cornelissen, P, Stein, A (2008). A specific and rapid neural signature for parental instinct. PLOS ONE, 3, e1664.

Kringelbach, ML (2005). The human orbitofrontal cortex: Linking reward to hedonic experience. Nat Rev Neurosci, 6, 691-702. Kringelbach, ML (2009). The pleasure center. Oxford, U.K: Oxford University Press.

Kringelbach, ML (2010). The hedonic brain: A functional neuroanatomy of human pleasure. In Kringelbach, Berridge (Ed.), Pleasures of the brain (pp. 202-221). Oxford, U.K: Oxford University Press.

Kringelbach, ML, \& Berridge, KC (2009). Towards a functional neuroanatomy of pleasure and happiness. Trends Cog Sci, 13, 479-487.

Kringelbach, ML, \& Berridge, KC (2010). The functional neuroanatomy of pleasure and happiness. Discov Med, 9, 579-587.

Kringelbach, ML, Berridge, KC, (Eds) (2010). Pleasures of the brain. Oxford: Oxford University Press.

Kringelbach, ML, Green, AL, Owen, SL, Schweder, PM, Aziz, TZ (2010). Sing the mind electric - principles of deep brain stimulation. Eur J Neurosci, 32, 1070-1079.

Kringelbach, ML, Jenkinson, N, Green, AL, Owen, SL, Hansen, PC, Cornelissen, PL, Holliday, IE, Stein, J, Aziz, TZ (2007). Deep brain stimulation for chronic pain investigated with magnetoencephalography. Neuroreport, 18, 223-228.

Kringelbach, ML, Jenkinson, N, Owen, SL, Aziz, TZ (2007). Translational principles of deep brain stimulation. Nat Rev Neurosci, 8, 623-635.

Kringelbach, ML, O'Doherty, J, Rolls, ET, Andrews, C (2003). Activation of the human orbitofrontal cortex to a liquid food stimulus is correlated with its subjective pleasantness. Cereb Cortex, 13, 1064-1071.

Kringelbach, ML, Pereira, EAC, Green, AL, Owen, SLF, Aziz, TZ (2009). Deep brain stimulation for chronic pain. Journal of Pain Management, 3, 301-314.

Kringelbach, ML, \& Rolls, ET (2004). The functional neuroanatomy of the human orbitofrontal cortex: Evidence from neuroimaging and neuropsychology. Prog Neurobiol, 72, 341-372.

Kuppens, P, Realo, A, Diener, E (2008). The role of positive and negative emotions in life satisfaction judgment across nations. $J$ Pers Soc Psychol, 95, 66-75.

Laureys, S, Perrin, F, Faymonville, ME, Schnakers, C, Boly, M, Bartsch, V, Majerus, S, Moonen, G, Maquet, P (2004). Cerebral processing in the minimally conscious state. Neurology, 63, 916-918.

Lawrence, AD, Evans, AH, Lees, AJ (2003). Compulsive use of dopamine replacement therapy in parkinson's disease: Reward systems gone awry? Lancet Neurology, 2, 595-604.

Leknes, S, \& Tracey, I (2008). A common neurobiology for pain and pleasure. Nat Rev Neurosci, 9, 314-320.

Leknes, S, \& Tracey, I (2010). Pleasure and pain: Masters of mankind. In Kringelbach, Berridge (Ed.), Pleasures of the brain (pp. 320-336). Oxford, U.K.: Oxford University Press.

Leyton, M (2010). The neurobiology of desire: Dopamine and the regulation of mood and motivational states in humans. In Kringelbach, Berridge (Ed.), Pleasures of the brain (pp. 222-243). Oxford, U.K.: Oxford University Press.

Lou, HC, Kjaer, TW, Friberg, L, Wildschiodtz, G, Holm, S, Nowak, M (1999). A 150-h2o pet study of meditation and the resting state of normal consciousness. Hum Brain Mapp, 7, 98-105.

Lozano, AM, Mayberg, HS, Giacobbe, P, Hamani, C, Craddock, RC, Kennedy, SH (2008). Subcallosal cingulate gyrus deep brain stimulation for treatment-resistant depression. Biol Psychiatry, 64, 461-467.

Lundy, RF Jr (2008). Gustatory hedonic value: Potential function for forebrain control of brainstem taste processing. Neurosci Biobehav Rev, 32, 1601-1606

Mahler, SV, Smith, KS, Berridge, KC (2007). Endocannabinoid hedonic hotspot for sensory pleasure: Anandamide in nucleus accumbens shell enhances 'liking' of a sweet reward. Neuropsychopharmacology, 32, 2267-2278.

Merker, B (2007). Consciousness without a cerebral cortex: A challenge for neuroscience and medicine. Behav Brain Sci, 30, 63-81, discussion 81-134.

Mill, JS, Crisp, R, NetLibrary Inc. (1998). Utilitarianism. Oxford: Oxford University Press.

Miller, J, Vorel, S, Tranguch, A, Kenny, E, Mazzoni, P, van Gorp, W, Kleber, H (2006). Anhedonia after a selective bilateral lesion of the globus pallidus. Am J Psychiatry, 163, 786-788.

Mitterschiffthaler, MT, Kumari, V, Malhi, GS, Brown, RG, Giampietro, VP, Brammer, MJ, Suckling, J, Poon, L, Simmons, A, Andrew, C, Sharma, T (2003). Neural response to pleasant stimuli in anhedonia: An fmri study. Neuroreport, 14, 177-182.

Nesse, RM (2002). Evolutionary biology: A basic science for psychiatry. World Psychiatry, 1, 7-9.

Niv, Y, Daw, ND, Joel, D, Dayan, P (2007). Tonic dopamine: Opportunity costs and the control of response vigor. Psychopharmacology (Berl), 191, 507-520.

Oishi, S, Diener, E, Lucas, RE (2007). The optimum level of well-being can people be too happy? Perspect Psychol Sci, 2, $346-360$.

Olds, J (1956). Pleasure centers in the brain. Sci Am, 195, 105-116.

Olds, J, \& Milner, P (1954). Positive reinforcement produced by electrical stimulation of septal area and other regions of rat brain. J Comp Physiol Psychol, 47, 419-427.

Palmiter, RD (2007). Is dopamine a physiologically relevant mediator of feeding behavior? Trends Neurosci, 30, 375-381.

Panksepp, J (1998). Affective neuroscience: The foundations of human and animal emotions. Oxford, U.K.: Oxford University Press.

Panksepp, J (2007). Neurologizing the psychology of affects: How appraisal-based constructivism and basic emotion theory can coexist. Perspect Psychol Sci, 2, 281-296.

Pecina, S (2008). Opioid reward 'liking' and 'wanting' in the nucleus accumbens. Physiol Behav, 94, 675-680.

Peciña, S, \& Berridge, KC (2005). Hedonic hot spot in nucleus accumbens shell: Where do mu-opioids cause increased hedonic impact of sweetness? J Neurosci, 25, 11777-11786.

Pecina, S, \& Smith, KS (2010). Hedonic and motivational roles of opioids in food reward: Implications for overeating disorders. Pharmacol Biochem Behav, 97, 34-46.

Peciña, S, Smith, KS, Berridge, KC (2006). Hedonic hot spots in the brain. Neuroscientist, 12, 500-511.

Portenoy, RK, Jarden, JO, Sidtis, JJ, Lipton, RB, Foley, KM, Rottenberg, DA (1986). Compulsive thalamic self-stimulation: A case with metabolic, electrophysiologic and behavioral correlates. Pain, 27, 277-290.

Rahman, S, Robbins, TW, Sahakian, BJ (1999). Comparative cognitive neuropsychological studies of frontal lobe function: Implications for therapeutic strategies in frontal variant frontotemporal dementia. Dement Geriatr Cogn Disord, 10 (Suppl 1), 15-28. 
Redgrave, P, \& Gurney, K (2006). The short-latency dopamine signal: A role in discovering novel actions? Nat Rev Neurosci, 7, 967-975.

Robbins, TW, \& Everitt, BJ (2007). A role for mesencephalic dopamine in activation: Commentary on berridge (2006). Psychopharmacology (Berl), 191, 433-437.

Robinson, TE, \& Berridge, KC (1993). The neural basis of drug craving: An incentive-sensitization theory of addiction. Brain Res Rev, 18, 247-291.

Robinson, TE, \& Berridge, KC (2003). Addiction. Annu Rev Psychol, 54, 25-53.

Rolls, ET (2005). Emotion explained. Oxford; New York: Oxford University Press.

Rozin, P (1999). Preadaptation and the puzzles and properties of pleasure. In Kahneman, Diener, Schwarz (Ed.), Well-being: The foundations of hedonic psychology (pp. 109-133). New York: Russell Sage Foundation.

Ryle, G (1954). Pleasure. Proceedings of the Aristotelian Society, 28, 135-146.

Salamone, JD, Correa, M, Farrar, A, Mingote, SM (2007). Effort-related functions of nucleus accumbens dopamine and associated forebrain circuits. Psychopharmacology (Berl), 191, 461-482.

Salimpoor, VN, Benovoy, M, Larcher, K, Dagher, A, Zatorre, RJ (2011). Anatomically distinct dopamine release during anticipation and experience of peak emotion to music. Nat Neurosci, 14, 257-262.

Schacter, DL, Addis, DR, Buckner, RL (2007). Remembering the past to imagine the future: The prospective brain. Nat Rev Neurosci, 8, 657-661.

Schlaepfer, T, Cohen, M, Frick, C, Kosel, M, Brodesser, D, Axmacher, N, Joe, A, Kreft, M, Lenartz, D, Sturm, V (2008). Deep brain stimulation to reward circuitry alleviates anhedonia in refractory major depression. Neuropsychopharmacology, 33, 368-377.

Schlaepfer, TE, Cohen, MX, Frick, C, Kosel, M, Brodesser, D, Axmacher, N, Joe, AY, Kreft, M, Lenartz, D, Sturm, V (2007). Deep brain stimulation to reward circuitry alleviates anhedonia in refractory major depression. Neuropsychopharmacology, 33(2), 368-77.

Schnider, A (2003). Spontaneous confabulation and the adaptation of thought to ongoing reality. Nat Rev Neurosci, 4, $662-671$.

Schulkin, J (2004). Allostasis, homeostasis, and the costs of physiological adaptation. New York: Cambridge University Press.

Schultz, W, Dayan, P, Montague, PR (1997). A neural substrate of prediction and reward. Science, 275, 1593-1599.

Seligman, MEP, Steen, TA, Park, N, Peterson, C (2005). Positive psychology progress - empirical validation of interventions. Am Psychol, 60, 410-421.

Shewmon, DA, Holmes, GL, Byrne, PA (1999). Consciousness in congenitally decorticate children: Developmental vegetative state as selfffulfilling prophecy. Dev Med Child Neurol, 41, 364-374.

Shizgal, P, Fulton, S, Woodside, B (2001). Brain reward circuitry and the regulation of energy balance. Int J Obes, 25, S17-S21.

Sienkiewicz-Jarosz, H, Scinska, A, Kuran, W, Ryglewicz, D, Rogowski, A, Wrobel, E, Korkosz, A, Kukwa, A, Kostowski, W, Bienkowski, P (2005). Taste responses in patients with parkinson's disease. J Neurol Neurosurg Psychiatry, 76, 40-46.

Skov, M (2010). The pleasures of art. In Kringelbach, Berridge (Ed.), Pleasures of the brain (pp. 270-286). Oxford, U.K.: Oxford University Press.

Smith, KS, \& Berridge, KC (2005). The ventral pallidum and hedonic reward: Neurochemical maps of sucrose "Liking" And food intake. J Neurosci, 25, 8637-8649.

Smith, KS, \& Berridge, KC (2007). Opioid limbic circuit for reward: Interaction between hedonic hotspots of nucleus accumbens and ventral pallidum. J Neurosci, 27, 1594-1605.

Smith, KS, Berridge, KC, Aldridge, JW (2011). Disentangling pleasure from incentive salience and learning signals in brain reward circuitry. Proc Natl Acad Sci USA, 108, E255-264.

Smith, KS, Mahler, SV, Pecina, S, Berridge, KC (2010). Hedonic hotspots: Generating sensory pleasure in the brain. In Kringelbach, Berridge (Ed.), Pleasures of the brain (pp. 27-49). Oxford, U.K.: Oxford University Press.

Steele, JD, Christmas, D, Eljamel, MS, Matthews, K (2008). Anterior cingulotomy for major depression: Clinical outcome and relationship to lesion characteristics. Biol Psychiatry, 63, 670-677.

Steiner, JE (1973). The gustofacial response: Observation on normal and anencephalic newborn infants. Symposium on Oral Sensation and Perception, 4, 254-278.

Steiner, JE, Glaser, D, Hawilo, ME, Berridge, KC (2001). Comparative expression of hedonic impact: Affective reactions to taste by human infants and other primates. Neurosci Biobehav Rev, 25, 53-74.

Teasdale, JD, Segal, ZV, Williams, JM, Ridgeway, VA, Soulsby, JM, Lau, MA (2000). Prevention of relapse/recurrence in major depression by mindfulness-based cognitive therapy. I Consult Clin Psychol, 68, 615-623.

Tindell, AJ, Smith, KS, Pecina, S, Berridge, KC, Aldridge, JW (2006). Ventral pallidum firing codes hedonic reward: When a bad taste turns good. J Neurophysiol, 96, 2399-2409.

Treadway, MT, \& Zald, DH (2011). Reconsidering anhedonia in depression: Lessons from translational neuroscience. Neurosci Biobehav Rev, 35, 537-555.

Tucker, DM, Luu, P, Pribram, KH (1995). Social and emotional self-regulation. Ann N Y Acad Sci, 769, 213-239.

Urry, HL, Nitschke, JB, Dolski, I, Jackson, DC, Dalton, KM, Mueller, CJ, Rosenkranz, MA, Ryff, CD, Singer, BH, Davidson, RJ (2004). Making a life worth living: Neural correlates of well-being. Psychol Sci, 15, 367-372.

Urry, HL, van Reekum, CM, Johnstone, T, Kalin, NH, Thurow, ME, Schaefer, HS, Jackson, CA, Frye, CJ, Greischar, LL, Alexander, AL, Davidson, RJ (2006). Amygdala and ventromedial prefrontal cortex are inversely coupled during regulation of negative affect and predict the diurnal pattern of cortisol secretion among older adults. J Neurosci, 26, 4415-4425.

Valenstein, ES (1986). Great and desperate cures: The rise and decline of psychosurgery and other radical treatments for mental illness. New York: Basic Books.

Valenstein, ES, \& Cox, VC (1970). Influence of hunger, thirst, and previous experience in the test chamber on stimulus-bound eating and drinking. J Comp Physiol Psychol, 70, 189-199.

van Reekum, CM, Urry, HL, Johnstone, T, Thurow, ME, Frye, CJ, Jackson, CA, Schaefer, HS, Alexander, AL, Davidson, RJ (2007). Individual differences in amygdala and ventromedial prefrontal cortex activity are associated with evaluation speed and psychological well-being. J Cogn Neurosci, 19, 237-248.

Veldhuizen, MG, Rudenga, KJ, Small, D (2010). The pleasure of taste flavor and food. In Kringelbach, Berridge (Ed.), Pleasures of the brain (pp. 146-168). Oxford, U.K.: Oxford University Press. 
Voon, V, Kubu, C, Krack, P, Houeto, JL, Troster, Al (2006). Deep brain stimulation: Neuropsychological and neuropsychiatric issues. Mov Disord, 21 (Suppl 14), S305-327.

Vuust, P, \& Kringelbach, ML (2010). The pleasure of music. In Kringelbach, Berridge (Ed.), Pleasures of the brain (pp. 255-269). Oxford, U.K.: Oxford University Press.

Wichmann, T, \& DeLong, MR (2006). Deep brain stimulation for neurologic and neuropsychiatric disorders. Neuron, 52, 197-204.

Wiers, RW, Bartholow, BD, van den Wildenberg, E, Thush, C, Engels, RC, Sher, KJ, Grenard, J, Ames, SL, Stacy, AW (2007). Automatic and controlled processes and the development of addictive behaviors in adolescents: A review and a model. Pharmacol Biochem Behav, 86, 263-283.

Wiers, RW, Stacy, AW, (Eds) (2006). Handbook of implicit cognition and addiction. Thousand Oaks, California: Sage Publications, Inc.

Willoch, F, Schindler, F, Wester, HJ, Empl, M, Straube, A, Schwaiger, M, Conrad, B, Tolle, TR (2004). Central poststroke pain and reduced opioid receptor binding within pain processing circuitries: A [11c]diprenorphine pet study. Pain, 108, 213-220

Winkielman, P, Berridge, KC, Wilbarger, JL (2005). Unconscious affective reactions to masked happy versus angry faces influence consumption behavior and judgments of value. Pers Soc Psychol Bull, 31, 121-135.

Wise, RA (1985). The anhedonia hypothesis: Mark iii. Behav Brain Sci, 8, 178-186.

Zhang, J, Berridge, KC, Tindell, AJ, Smith, KS, Aldridge, JW (2009). A neural computational model of incentive salience. PLoS Comput Biol, 5, e1000437.

doi:10.1186/2211-1522-1-3

Cite this article as: Berridge and Kringelbach: Building a neuroscience of pleasure and well-being. Psychology of WellBeing: Theory, Research and Practice 2011 1:3.

\section{Submit your manuscript to a SpringerOpen ${ }^{\odot}$} journal and benefit from:

- Convenient online submission

- Rigorous peer review

- Immediate publication on acceptance

- Open access: articles freely available online

- High visibility within the field

- Retaining the copyright to your article

Submit your next manuscript at $\gg$ springeropen.com 